\title{
The Concept of 'Work' in CSCW
}

\author{
Kjeld Schmidt \\ Department of Organization, Copenhagen Business School, Copenhagen, Denmark
}

\begin{abstract}
The scope of CSCW, its focus on work, has been a topic of sporadic debate for many years indeed, from the very beginning in the late 1980s. But in recent years the issue has become one of general concern. Most of this debate has been taking place in closed fora such as program committees, editorial boards, and email discussion groups, but over the last few years the debate has been brought out in the open in a few publications, in particular in a programmatic article from 2005 by three esteemed CSCW researchers: Andy Crabtree, Tom Rodden, and Steve Benford. They argue that CSCW should 'move its focus away from work'. Other researchers argue along the same lines. Taking this open challenge as a welcome cue, the present article addresses CSCW's scope: the rationale for its focus on ordinary work. After an initial discussion of the arguments put forward by Crabtree et al. and by others, the article focuses on an analysis of the concept of 'work', drawing on the methods and insights of 'ordinary language philosophy', and, flowing from this, a critique of the notion of 'work' in conversation analysis. After a critical appraisal of prevailing myths about the realities of work in the contemporary world, the article ends in an attempt to position CSCW in the context of technological development more broadly. The underlying premise of the article is that it is time to reconsider CSCW: to rethink what it is and why it might be important.
\end{abstract}

It is hardly controversial to say that our understanding of work practices has become significantly more realistic and sophisticated over the last two decades or so. It is hardly controversial, either, to say that CSCW has been a major force in bringing this about. The intellectualist and mechanistic (or 'cognitivist') notions and theories of orderly activities that only one or two decades ago seemed unassailable and unquestionable have been upset and, by and large, overthrown. By virtue of its commitment to the development of new classes of information technology, CSCW has succeeded in situating technology in the context of ordinary practical activities in their material settings. As part of this effort, CSCW researchers have developed conceptual frameworks and investigative strategies and techniques that, however tentative they may be, enable us to hone in on the ways in which mundane coordinative artifacts and clusters of such artifacts are deployed and developed by practitioners. In doing so, CSCW researchers have set a new standards for rigorous analysis of actual work practices. And complementary to these achievements, CSCW has articulated (in outline, at least) a critique of fundamental assumptions and tenets in computing technologies and has fostered promising lines of technological development in areas such as 'awareness' mechanisms and flexible workflows.

However, these achievements are overshadowed by retrograde developments in the form of, for example, the increasing emphasis on studies of on-line behavior in 'social media' and similar uses of well known message exchange and file 
sharing technologies. Such behavioral studies, of little or no relevance for the development of new collaboration technologies, now dominate the ACM CSCW conferences. (For a critique of these developments, cf. Schmidt 2009).

At the same time, and related to this, doubts about the direction and scope of CSCW, especially the field's declared focus on 'work', have been building over years. These misgivings were mostly uttered and debated in closed fora such as program committees, editorial boards, and ad hoc email discussion groups, and have only occasionally been articulated in public fora. It was, for example, the designated topic of a panel discussion at ECSCW 2003 in Helsinki, Finland, organized by Geraldine Fitzpatrick and Paul Dourish. The issue of the scope of CSCW was also debated in a more general panel discussion at ECSCW 2007 in Limerick, Ireland, organized by Liam Bannon. And most recently, the issue of 'work' in CSCW was debated intensely at a 'Town Hall Meeting' at CSCW 2010 in Savannah, Georgia, and in a subsequent flurry of widely distributed emails. It is a telling sign of the thrust of these efforts that the Springer CSCW book series was recently re-baptized so that the acronym 'CSCW' now reads 'Collaboration, Sociality, Computation, and the Web', 1 and while the Call for Participation for ACM CSCW 2011 noted that 'work is an important area of focus for the conference', 'work' in the Call for CSCW 2012 has been demoted to 'an area of focus'.'

Although these debates do not quite take place in the proverbial backroom full of cigar smoke, they are anyway not on public record, which hampers an open and systematic discussion about these critically important issues. Fortunately, three distinguished CSCW researchers, namely, Andy Crabtree, Tom Rodden, and Steve Benford, have provided the $\mathrm{CSCW}$ community with a programmatic article in which they take the debate to the public forum (2005). For that they deserve unreserved credit. The same applies to Barry Brown and Louise Barkhuus who argue along parallel lines in their introduction to the special issue of the CSCW Journal on 'Leisure and CSCW' (2007).

\section{The horse is out of the barn!}

The persistent misgivings and protracted debates demonstrate that CSCW's program needs clarification. It is time to reconsider CSCW, to rethink what it is and why it might be important, and it is time to do so in a public forum. This paper will focus on CSCW's scope: the rationale for its focus on ordinary work. ${ }^{3}$

The paper falls into four - distinctly different—-sections. The first discusses the issues raised by Crabtree and others and focuses on the arguments put forward for the assertion that CSCW's research program should no longer focus on work. The second section is devoted to the concept of 'work', its meaning. The aim is not to stipulate CSCW's research program on the basis of a conceptual analysis (which would be a non sequitur) but to outline the meaning of 'work' so that we know what we mean when we debate whether or not CSCW's focus should move away from work. Section 3, by contrast, focuses on various underlying assumptions about the realities of working life: that industrial society is a thing of the past and that we now live in 'the information society' or something similar and that work is somehow of diminishing importance relative to 
domestic life and 'ludic pursuits'. The fourth and last section briefly discusses CSCW's place in the greater scheme of things: its place vis-à-vis the development of computing technologies. In so doing, Section 4 presents, in a constructive manner, an attempt to articulate CSCW's research program, albeit in outline (for a more elaborate discussion of CSCW's research program, cf. Schmidt 2011).

\section{Moving with the times, blowing in the wind}

The first item on the agenda is to examine the arguments that are being offered for changing the scope of CSCW.

Crabtree and his colleagues do not beat around the bush. Under the title 'Moving with the times', which is obviously meant to resonate Dylan's clarion call ('And the first one now/Will later be last/For the times they are a-changin'), the article states its message forcefully already in the abstract:

it is no mere accident that CSCW took work as its topic and resource-the historical nature of IT research from which the field emerged meant that for all practical purposes it could not be otherwise. Yet times change. IT research moves on. Today mobile, ambient, pervasive, ubiquitous, mixed reality and wearable computing, et cetera, are of fundamental concern to the contemporary computing research community. Furthermore, these developments are accompanied by a movement away from the workplace to focus on diverse settings in everyday life: homes, games, museums, photography, tourism, performances, indeed diverse bodies of people and pursuits that generally fall under the conceptual rubric of the "ludic". Accompanying this shift away from work is a call for new approaches and concepts that will enable researchers to better understand the ludic and inform design appropriately. (Crabtree et al. 2005, p. 217)

The prophetical rhetoric is obviously intended to convey a notion of ineluctable fate: 'times change' and 'IT research moves on' ('you better start swimmin"). Invoking 'The Development' and other forms of hype is very much like military march music and battle cries; it is meant to encourage the faint-hearted ('We'll be victorious!') and to intimidate the opposition ('Resistance is futile!'). New technologies, we are told, are emerging that are 'of fundamental concern to the [sic] contemporary computing research community'. And nothing less than 'a movement away from the workplace' is taking place, shifting the 'focus' from work to 'diverse settings in everyday life', and this 'shift away from work' is accompanied by 'a call for new approaches and concepts that will enable researchers to better understand the ludic'. In short, we are told, 'move with the times' ('or you'll sink like a stone').

Pipes and drums notwithstanding, the three authors are already slightly less confident in the last section of the article. Here CSCW no longer has to 'shift its focus away from work', nor does it have to 'radically reshape itself in order to tackle these new areas of interest' (p. 247). Rather, 'the horizon should be broadened' to 'incorporate' 'ludic 
pursuits'. But this is just a change in tone, not in substance. The basic argument is that new information technologies require the scope of $\mathrm{CSCW}$ to be altered significantly.

Their argument runs like this:

Contemporary IT research agendas are concerned with the development of such technologies as mobile, mixed reality, ambient, pervasive, ubiquitous, and wearable computing systems, devices, applications, and architectures. Visions of these technologies often hinge on notions of ubiquitous or pervasive computing where technology is interleaved with our everyday activities, located in the places where we live, work and play. The need for these technologies to be situated in our everyday lives suggests that many of the lessons learned in CSCW about the sociality of work are salient to ongoing developments in these and other emerging areas of IT research. To explore the salience of CSCW in such contexts will require the field to extend its boundaries and broaden its horizons beyond the bounds of the workplace, however (Crabtree et al. 2005, pp. 218f.).

Accordingly, they argue, CSCW should shift its focus from work to 'homes, games, museums, photography, tourism, performances, indeed diverse bodies of people and pursuits that generally fall under the conceptual rubric of the "ludic" (p. 217). ${ }^{4}$ They elaborate this proposal:

while ludic pursuits may be essentially "playful" in character they are nonetheless socially organized and it is this that makes them available to $\mathrm{CSCW}$ research. Furthermore, the need for new technologies to be situated within these diverse activities strongly aligns this research with the underpinning motivation of $\mathrm{CSCW}$ to develop technologies that are situated within real world activities and informed by our understanding of the socially organized nature of those activities. (Crabtree et al. 2005, pp. 219f.)

The gist of what the authors are saying can be summarized in two arguments:

(1) The first argument, the one to which the bulk of their paper is devoted, is that 'ludic pursuits' and other domains of activity beyond ordinary work settings are 'available to CSCW research' because they are 'socially organized' (pp. 219, 247).

(2) The second argument is that CSCW is to be demarcated in terms of certain technologies. Their argument, stated clearly and repeatedly, is that because of these new technologies CSCW should abandon or broaden its scope, 'shift away from work' (p. 218) or, less drastically, 'broaden' its horizon (p. 247). Condensed, the argument is this: (a) CSCW was and should remain 'thoroughly intertwined with IT research'; (b) IT research now 'moves out from the workplace to consider how IT may be situated in a broader range of social settings'; (c) therefore CSCW 'must also move with it' (p. 247).

I will deal with these issues in turn.

The general argument advanced by Crabtree et al. seems to be shared by significant sections of the CSCW community. It is for example echoed by Barry Brown and Louise Barkhuus: 'Our goal $[\ldots]$ has been $[\ldots]$ not simply to move $\mathrm{CSCW}$ into studying 
leisure, entertainment and pleasure but to explore the new contributions and outputs from our research' $(2007$, p. 8). Citing the article by Crabtree et al. they state:

The interdependences between work and leisure cuts across many core concerns of CSCW: awareness, division of labour, collaboration, distribution of tasks, efficiency and even workflow. These exist in our leisure lives as much as [in] our work [...]. It is not that leisure is exactly like paid employment, but rather that many of the concepts of CSCW are concepts of collaborative organization. As such, leisure can depend upon this organization as much as work, giving CSCW leverage in understanding, and designing for, this domain of activity (Brown and Barkhuus 2007, p. 3)

However, Brown and Barkhuus are more circumspect in their discussion, in that they remain aware of the 'irony in how a field such as $\mathrm{CSCW}$, and the concepts it has developed, have turned out to be of relevance when looking at leisure', and they caution that 'studying leisure demands that we consider aspects of practice, such as happiness and enjoyment, as much as effectiveness or efficiency' (p. 7). This leads them to suggest that the issue that should be explored is: 'How can our methods help develop enjoyable and not just effective systems? How can we explore enjoyment as a broad research goal?' (p. 8).--If these questions are researchable questions at all (which I seriously doubt), are they issues that can be accommodated within a practiceoriented research program of $\mathrm{CSCW}$ without depriving the program of practical relevance and orientation? And at another level of abstraction, are we now, after all these years, supposed to again embrace the scientistic myth of a universal method?

\subsection{Making the phenomenon disappear}

Let us consider the first argument, namely, that 'ludic pursuits' are 'available to CSCW research' because they are 'socially organized'. This argument is formulated as a reply to an objection to this program that was raised in 2001 by Bill Gaver who argued that 'ludic pursuits' are characterized by very different objectives, priorities, and criteria of validity compared to the world of ordinary work: 'There is a danger that as technology moves from the office into our homes, it will bring along with it workplace values such as efficiency and productivity at the expense of other possibilities. People do not just pursue tasks and solve problems, they also explore, wonder, love, worship, and waste time' (Gaver 2001). Gaver restated and elaborated this objection in 2002: 'As collaborative technologies move out of the office and into the home or local community, new goals emerge, and thus new requirements for information and media. At home technologies could support emotional connections, providing access to other peoples' moods or attitudes, not simply their presence or availability. Within the community, technologies might help bridge different social groups, values and attitudes, to potentially mediate the communication of varied subcultures.' (Gaver 2002, p. 477). In short, Gaver is warning that the concept of working and the concepts of exploration, wondering, loving, worshipping, and wasting time cannot simply be assimilated, as these different domains are 
characterized by different criteria, priorities, values, attitudes, and so on. Gaver could have said simply that we must be careful not to make 'the phenomenon disappear', to use a key expression from ethnomethodology (Sharrock and Anderson 1986).

Nevertheless, Crabtree et al. argue that it is indeed possible to 'unpack the social characteristics of ludic pursuits using existing CSCW concepts' such as 'routines', 'constant interruption', 'distributed awareness', 'local knowledge', 'surreptitious monitoring' ( $p, 248)$. To support this, they present a study of a game and then show that such CSCW concepts can be applied to the data. They are indeed able to recognize 'routines', 'constant interruption', 'distributed awareness', 'local knowledge', 'surreptitious monitoring' in the way the players go about doing the game. Indeed! They conclude from this that 'ludic pursuits' and other domains of activity beyond ordinary work settings are 'available to CSCW research' because they are 'socially organized'; that is, such activities also 'rely on, exploit, and exhibit their sociality as a condition of their intelligibility, meaningfulness and value' (pp. 219, 247). Hence, they argue, CSCW can shift or widen its focus to address 'socially organized activities' in all generality without confounding what we normally would consider quite different domains.

This argument is immediately and obviously absurd, for Gaver did not claim that such CSCW concepts cannot be applied beyond the domain of work. He argued that doing so would make the phenomenon disappear, namely, the phenomena of playing games, of horsing around, of worshipping, etc. Doing so would not yield an adequate picture of the phenomenon (playing games, etc.). And in fact, in presenting their study and in applying CSCW concepts to the case, Crabtree, Rodden, and Benford do not manage to give us an inkling as to whether the players were having fun! They do not seem to have realized that they would have to do just that to demonstrate that Gaver was unduly worried. As it is, then, Gaver's objection still stands.

Anyway, our concern here is of course what it would do to CSCW if its scope is extended and broadened, as called for by Crabtree et al. My answer is that for $\mathrm{CSCW}$ the phenomenon would disappear.

Now, what is 'the phenomenon' and what does it mean for it to 'disappear'? To answer that, let us first consider the key phenomenological notion of the "natural attitude'. In view of the historical role the founder of phenomenological sociology, Alfred Schutz, has played in the development of the sociology of ordinary practices (from Garfinkel (1967) to Bourdieu (1980)), it may be worthwhile to briefly summarize his view on 'the natural attitude' of working.

The everyday world of working plays a key role in the thinking of Schutz, and he discusses the concept of working in many key places. 'We begin with an analysis of the world of daily life which the wide-awake, grown-up man who acts in it and upon it amidst his fellow-men experiences within the natural attitude as a reality,' goes a typical beginning of a Schutzian argument. He then goes on to describe this natural attitude of a person engaged in his or her daily work:

To [the natural attitude] the world is from the outset not the private world of the single individual but an intersubjective world, common to all of us, in 
which we have not a theoretical but an eminently practical interest. The world of everyday life is the scene and also the object of our actions and interactions. We have to dominate it and we have to change it in order to realize the purposes which we pursue within it among our fellow-men. We work and operate not only within but upon the world. Our bodily movementskinaesthetic, locomotive, operative-gear, so to speak, into the world, modifying or changing its objects and their mutual relationships. On the other hand, these objects offer resistance to our acts which we have either to overcome or to which we have to yield. Thus, it may be correctly said that a pragmatic motive governs our natural attitude toward the world of daily life. World, in this sense, is something that we have to modify by our actions or that modifies our actions. (Schütz 1945, pp. 208f.)

In this particular context, Schutz wants to contrast the world of work and its natural attitude with other regions of human experience. Schutz here takes his cue from some comments that William James made in his Principles of Psychology on different experiential 'sub-universes', such as the world of physical things, the world of ideas, the worlds of mythology and religion, or the world of 'sheer madness' (James 1890, Chapter 21). Schutz wants to 'free this important insight from its psychologistic setting' and therefore proposes the term 'finite provinces of meaning', mentioning as examples, in addition to the world of working, 'the world of dreams, of imageries and phantasms, especially the world of art, the world of religious experiences, the world of scientific contemplation, the play world of the child, and the world of the insane' (Schütz 1945, pp. 229f.). The major difference between the world of working and these 'finite provinces of meaning' is that 'the epoché of the natural attitude' of the world of working is replaced by 'other epochés which suspend belief in more and more layers of the reality of the daily life, putting them in brackets' (p. 233). 'The world of working in daily life is the archetype of our experience of reality. All the other provinces of meaning may be considered its modifications' (p. 233). For Schutz, that is, the world of working - the world of embodied socially situated material activities - stands out as 'paramount' because 'We have an eminently practical interest in it, caused by the necessity of complying with the basic requirements of our life' (p. 226f.). In short, if we follow Schutz' train of thoughts, the distinction between the world of working and those other 'provinces of meaning' is critical to the project of phenomenological sociology, because without it the essential insight expressed in the concept of 'the natural attitude' is blowing in the wind, down the drain, gone.

But what is now being proposed is just that: to move or widen the scope of $\mathrm{CSCW}$ to include, without discrimination or ranking, on an equal footing with ordinary cooperative work, 'socially organized activities' of whatever 'finite province of meaning': 'ludic pursuits' like playing games, watching daytime TV, playing the Ancient World of Warcraft, but presumably also-why not?daydreaming, courting, pillow talk, praying for redemption. 
The universalistic impulses of mainstream sociology-its aspirations to produce supra-historical propositions about 'the social' and its concomitant belief in universally applicable methods - are strong, and it is therefore perhaps not surprising that a later paper by Andy Crabtree together with Tom Rodden, Peter Tolmie, and Graham Button completely succumbs to this urge:

The purchase that ethnography has in design at present is one that is largely associated with studies of situated action. These are also called "ethnomethodologically-informed ethnographies", "studies of work" or "work-practice". Historically, they are closely allied with the development of workplace systems. It might be assumed that new contexts of design demand more of ethnography than work-practice studies to understand user needs. However, this would be to assume that somehow or other the analytic practices of ethnography in the workplace are different to the analytic practices of ethnography in, for example, the home or the museum. (Crabtree et al. 2009, p. 880 . - Citations omitted).

This position is perfectly clear. According to Crabtree et al. 'the analytic practices of ethnography in the workplace' are not 'different to the analytic practices of ethnography in, for example, the home or the museum'.--True, one can certainly subject ordinary work, domestic settings, and 'ludic pursuits' to the same 'analytical practices', but then one has also, already, $a b$ initio, assimilated the dissimilar.

A small anecdote may help to illuminate what is at stake. In 1954, Fred Strodtbeck invited Harold Garfinkel to join his jury project and, together with Saul Mendlovitz, listen to recordings of deliberations in a jury room. Garfinkel later recounted:

In 1954 Fred Strodtbeck was hired by the University of Chicago Law School to analyze tape recordings of jury deliberations obtained from a bugged jury room. Edward Shils was on the committee that hired him. When Strodtbeck proposed to a law school faculty to administer Bales Interaction Process Analysis categories, Shils complained: "By using Bales Interaction Process Analysis I'm sure we'll learn what about a jury's deliberations makes them a small group. But we want to know what about their deliberations makes them a jury". [...] Strodtbeck replied and Shils agreed: Shils was asking the wrong question! (Garfinkel et al. 1981, p. 133)

One may, of course, be able to identify features that are common to deliberations in 'small groups' such as juries and Tupperware parties, and one may, of course, be able to identify features that are common to 'socially organized activities' such as cooperative work settings and ludic pursuits, but then one has already, by methodological preference, decided against asking questions such as 'what makes the jury a jury' and what specifically characterizes cooperative work as opposed to 'socially organized activities' in all generality. 
One of ethnomethodology's most valuable contributions has been to challenge the assumption that different social domains can be investigated appropriately by applying a standard method (analytical stance, concepts, schemes). In fact, ethnomethodology has been so insistent on this principle ('Horses for courses!') that it brought onto itself that it could be criticized by conventional sociology for not being a cumulative endeavor but rather one marked by discontinuity. ${ }^{6}$

To illustrate the point, Sharrock and Anderson use sociological studies of the physician-patient relationship as an example, in particular Erving Goffman's remarks on the surgical theatre in his essay on 'Role distance' (Goffman 1961):

There Goffman reports that, in surgery, there is a great deal of byplay between the surgeon and the theatre staff, that the behaviour amongst medical staff there is more like that of Dr. Bob in the Muppet Show or of the Army surgeons in M.A.S.H., with lots of fooling about, than it is like that of those in more usual movie and television versions of operations - tense, serious affairs. However, whilst one thereby learns something about the theatre, one will learn nothing whatsoever from Goffman's essay about surgery itself. One learns nothing whatever about what, after all, the surgical staff are there to do and are doing. (Sharrock and Anderson 1986, p. 85).

That is, such strategies of inquiry 'make the phenomenon disappear' (p. 86). To show why such strategies lead to this, Sharrock and Anderson discuss the example of a study of medical encounters:

Suppose one sets out to study something like medicine, but is guided by the desire to look at the encounter in terms [of] (say) the general problems of organizing social interaction and in search of processes which may be found in any kind of social encounter, regardless of the business being transacted there. The fact that one is dealing with a medical encounter becomes a nuisance, something to be disregarded: after all, the things which are essential to it as a medical transaction are irrelevant to it as an instance of social interaction and attention on these peculiarities of it may obstruct and obscure our ability to see in the activity general and generic problems of organizing social action. Consequently, the fact that this is a medical encounter, specifically entered into for medical purposes and given its very life by the particularities which it does not share with going to the supermarket or having your shoes shined is almost completely marginal to the analysis. If you want to specify what it is that is distinctively medical about the transaction, you won't be able to get at it that way. (Sharrock and Anderson 1986, p. 86)

Sharrock and Anderson sum it up quite well:

Given that the methods have such a specific connection with the phenomenon under investigation there is no basis for any automatic assumption that they can be extended to other distinct phenomena. [...] A major change in its topic 
of inquiries may involve a new beginning, a search for the appropriate and distinctive method for the apprehension of this phenomena. At the very least, there must be continuing awareness of the temptation to import, through the adoption of an already-developed method, a set of inappropriate presumptions about the phenomenon and the proper form of inquiry into it. (Sharrock and Anderson 1986, p. 82)

By going down the path suggested by Crabtree and his colleagues, i.e., the path of assimilating the dissimilar, we would not only be causing confusion; we would be losing our ability to focus on exactly those practices that we find in complex cooperative work settings: the often elaborate coordinative practices (skills, typifications, techniques, schemes, notations, etc.) that have been developed to get the job done and get it done efficiently, well, timely, dependably, etc. We would produce accounts of work in which what is specific about work-about cooperative work in modern settings - is bracketed out, and we would instead come up with something akin to the vacuous accounts produced by mainstream sociology. In this regard, we have been duly warned by Sharrock and Anderson:

The things that characterize ordinary activities for those engaged in them seem to disappear whenever sociological theories and methods are brought into play. Whenever sociologists talk about family life, work, leisure and the rest, they seem to change the subject and discuss things that we as ordinary people would not recognize. In fact, in order to decipher what is being discussed, even sociologists have to refer back to their ordinary knowledge and experience of social life. (Sharrock and Anderson 1986, p. 15).

Only this time it seems as if ethnomethodology itself is being dressed up as yet another presumptively universal method that can be applied across the board, without alteration, irrespective of the specifics of the domain. Old habits certainly die hard.

\section{2. $\mathrm{CSCW}$ and technology development}

The second argument that is being expounded by Crabtree et al. (2005) concerns the relationship between CSCW and technology development.

Early in their article, the Crabtree et al. observe that $\mathrm{CSCW}$ was 'motivated and underpinned by advances in distributed computing and aligned with a number of technological research trajectories' (p. 218). This is not controversial at all; it is a historical fact. Without computers in networks, no CSCW. But the authors then begin to modulate their language: 'Technological developments and research played a central role in establishing a nascent field of interdisciplinary inquiry at the centre of which was a concerted effort to develop systems from these emerging technologies that would resonate with the social character of work and organization' (ibid.).- This is at first rather puzzling. Should this be read as 
implying that $\mathrm{CSCW}$ is about developing 'systems' (based on 'these emerging technologies') but has no role in developing 'technologies'? The difference is important. Do we have the requisite technologies and is the job simply restricted to configuring these technologies in the form of 'systems' for specific settings? If this reading is correct, how are the new technologies supposedly developed? Do the authors believe that they are and can be developed 'automatically' or 'spontaneously', that is, without a view to their potential application? Although not uncommon, this notion of a strictly unidirectional process of technological development, from mathematics to technologies in search of an application, is a fantasy. This reading is confirmed when the authors emphasize that

the historical context of interdisciplinary research, which underpinned the emergence and development of CSCW [...] was one motivated by the needs of IT researchers to understand the socially organized ("collaborative" or "cooperative") situations and settings in which developing systems would be deployed and used (p. 218.-Emphasis added).

This paints a strange picture of the roots of CSCW. It is a picture where 'technological development' and 'developing systems' were going concerns that simply happened to be in need of supplementary understanding of the settings 'in which developing systems would be deployed and used'. Were the then existing technologies adequate for 'designing systems' that 'resonate with the social character of work and organization'? Did CSCW just have to take the technologies and put them together?

In fact, this picture of the origins of $\mathrm{CSCW}$ is a gross misrepresentation. One example will suffice to show this (for a historical account, cf. Schmidt 2011, Chapter 11). If we take the classic CSCW article by Tom Rodden, John Mariani, and Gordon Blair from 1992, we will see a completely different view:

Cooperative applications which have started to emerge from CSCW research place new demands on the computer technology used to support them. These demands raise a number of fundamental questions about the way in which computing systems provide application support. [...] The majority of applications have been developed using existing and proven computer systems and technology. These supporting systems provide many of the services necessary to realise cooperative applications. However, the means by which these services are provided and the techniques used to present technological support to application developers incorporates an assumed model of use (Rodden et al. 1992, p. 41).

Calling for 'a re-consideration of the design decisions underpinning existing computer techniques', Rodden, Mariani, and Blair stated that: 'Many of these assumptions are challenged by the needs of cooperative applications which highlight a significant role for computer science research within CSCW and suggests that CSCW will have far reaching consequences for computing' (p. 42). 
As this one example amply demonstrates, CSCW from the very beginning did not merely take existing technologies for granted (apart from post hoc evaluation studies of the uses of 'groupware' and computer-mediated communications). On the contrary, progressive CSCW research questioned the 'assumed model of use'.

The making of CSCW was not incidentally connected to ordinary work. And indeed, Crabtree et al., state that 'it is no mere accident that CSCW took work as its topic and resource - the historical nature of IT research from which the field emerged meant that for all practical purposes it could not be otherwise' (p. 217), but then they go on to argue that it indeed was a 'mere accident' that CSCW 'took work as its topic and resource': 'Yet times change', and so on.

Anyway, the ' $\mathrm{W}$ ' in $\mathrm{CSCW}$ is not a historical accident. True, computer-mediated communication technologies such as messaging technologies (electronic mail, instant messaging, etc.) were developed by computer technicians for their own use in their own cooperative work (initially, the work of developing time-sharing operating systems, and later, network systems) and they predate the formation of CSCW as a research field by a couple of decades. As computer network infrastructures became established and widely accessible in the 1980s, it was soon clear that these technologies (which are as generic as pen and paper) were applicable not only to the work of computer scientists or to scientists in general but to all work domains and indeed universally applicable. Accordingly, as far as these technologies are concerned, the connection to ordinary work was a historical accident, just as it was a historical accident that integrated circuit technology was developed for digital wristwatches, microprocessor technology for desktop calculators, interactive computing for air defense systems, and so on. And it is also true that considerable research has been devoted to evaluating successive implementations and uses of computer-mediated communication technologies in different settings. But it was very early on realized that these technologies are of severely limited utility and scope in actual cooperative work settings in so far as they are not designed so that they can be integrated with the work tools and production equipment of these settings (CAD applications, etc.). That is, these technologies mediate communication divorced from actual cooperative work practices. This realization was clearly articulated by Irene Greif, who played the key part in the formation of CSCW as a research field in the 1980s. In the introduction to her classic collection of sources (1988), Greif wrote:

The technology of CSCW has some distinctive characteristics resulting from its focus on people and their working relationships. We can start by saying what $\mathrm{CSCW}$ is not. It is not simply electronic mail. Electronic mail is a useful general-purpose communication medium, designed for person-to-person messaging, adaptable through mailing-list capabilities to some group situations, but not really tuned (or tunable) to the needs of the work group. Computer conferencing systems come closer, because of the use of shared 
databases of messages, with access based on the roles of people in a group. (Greif 1988, pp. 6f.).

The same insight was expressed at the same time by European computermediated communications researchers (Bowers et al. 1988; Smith 1988; PankokeBabatz 1989). Greif also pointed out that multi-user databases systems suffer from comparable limitations:

Transaction-oriented database systems rely on "coordination technologies" for concurrency and access control and coordination is indeed fundamental to group work. However database coordination tools are in the hands of a database administrator rather than of the end-user, and are used more to keep people from inadvertently corrupting data than for the positive goal of having a workgroup build something together. (Greif 1988, p. 7).

When computer conferencing and other forms of computer-mediated communication technology is applied in cooperative work settings, 'the model breaks down' (p. 7):

The unstructured body of messages is suitable for the free-flowing text of natural language, but does not let us set the computer to work on our problems. Designers who draw pictures, software developers who jointly write code, financial analysts who collaborate on a budget - they all need coordination capabilities as an integral part of their work tools. That means coordination support within the CAD engineer's graphics package, within the programmer's source-code editor, within the budget writer's spreadsheet program. It means support for managing versions of objects, be they pictures, programs, or spreadsheets. It means ways to distribute parts of the object for work by contributing group members, ways to track the status of those distributed parts, ways to pull completed objects back together again. The limit of electronic mail and computer conferencing is that they have such features for managing messages only. CSCW widens the technology's scope of application to all the objects we deal with. (Greif 1988, pp. 7f.)

According to Greif, therefore, the central challenge for CSCW was to overcome a situation where 'information about group processes - speech acts, roles, and working relationships - is embedded in the application support tools' and instead provide 'common ways for users to deal with people-related aspects of their work across all their application systems' (Greif 1988, p. 7). Hence the central task for CSCW would be to widen 'the technology's scope of application' beyond messages 'to all the objects we deal with': 'Ideally these coordination tools should be implemented as reusable software modules that may not stand alone, but can be used by developers as components of other domain-specific products' (Greif 1988, p. 8).

It was also immediately realized that in order to develop computing technologies that support workers in communicating and coordinating with their 
colleagues from within and in terms of the tools and equipment of their practices, then systematic studies of actual cooperative work practices in real-world settings were required (Greif 1988; Pankoke-Babatz 1989). These insights then triggered the practice turn in $\mathrm{CSCW}$, the surge of ethnographic and similar workplace studies, and should be seen as the beginning of the CSCW research program proper. The technical research program that was outlined by Rodden, Mariani, and Blair in 1992 reflected these insights as well as the early ethnographic findings and was an important step in the elaboration of CSCW's research program.

In other words, CSCW's focus on work is not incidental by any measure but is determined by the rather mundane fact that orderly coordination and integration of cooperative work activities in modern work settings (in factories and design studios, in banks and on construction sites, in hospitals and research laboratories, and so on) require and rely on elaborate and often highly sophisticated coordinative practices and that these coordinative practices are inseparable from the specifics of the work processes and the tools and equipment of the trade. That is, coordinative practices are not generic but domain specific, and integrating communicational and coordinative functionality into domain-specific professional work tools and equipment is accordingly a crucial and preeminent challenge for developing IT for ordinary cooperative work settings. Thus, in order to develop the conceptual foundation for such technologies, in-depth studies of professional work and the concomitant coordinative practices are critically important. Hence the ' $\mathrm{W}$ ' in CSCW.

If it could be shown that ludic pursuits or domestic affairs are characterized by similarly elaborate coordinative practices and that these domains of activity require similar coordinative functionalities, then there would be no reason for $\mathrm{CSCW}$ to retain its focus on 'work'. But this is hardly the case. Ordinary cooperative work is the focal point of $\mathrm{CSCW}$ for the simple reason that cooperative work typically involve elaborate coordinative practices for which received computing technologies, the 'assumed model of use', are inadequate. In Greif's words, 'the model breaks down'.

What Crabtree, Rodden, and Benford now propose is a view of CSCW that is the diametrically opposite of the research program outlined some 20 years ago. On the view now propounded, CSCW is a field defined by a certain family of technologies and its role is to assist technological researchers in developing systems based on these technologies; the 'assumed model of use' is not questioned.

Crabtree et al. are of course correct in emphasizing the potentials of new interaction technologies such as mobile, ambient, pervasive, ubiquitous, mixed reality and wearable computing, etc. What they refer to is a family of technologies that, in different configurations, may make it possible to build applications that are both embedded in ordinary artifacts, typically mobile devices (handheld, wearable, etc.), and at the same time reactive to the state of the 
material environment. This family of technologies includes positioning based on any kind of wireless network (GPS, GSM, WiFi, Bluetooth, RFID), sensor and actuator technologies, multi-modal representations, and the like. By making it possible to build highly mobile and reactive devices these technologies may enable us to build applications that support 'mutual awareness' in ways that are far more effective and far less intrusive than previously (for fascinating examples, cf. Gaver 2002). After all, how much 'mutual awareness' can be obtained by means of a 17 inch screen, a keyboard, and a mouse? In short, these technologies are obviously quite relevant for ordinary cooperative work. They promise ways to facilitate 'mutual awareness' in settings in which the state of the physical environment and of actions in terms of location, movement, direction, velocity, temperature, etc. have practical significance for members: Where is part \#36.87.6745? Has it been moved? Whereto? Will the next shipment of cylinder blocks arrive on time? When will this process be finished? Has this roll been exposed to humidity? Is Mike from Maintenance on his way? Has he already been here?

But this is not the message Crabtree et al. want to convey. The potential application of these technologies in ordinary cooperative work settings is not even mentioned in the article. The message is the opposite: that CSCW must to shift the focus away from work or 'broaden' its horizon in order to accommodate these new interaction technologies. But this line of reasoning is a non sequitur. For the arrival of these technologies offer no reason whatsoever why CSCW should 'shift away from work'.

The fact that technologies developed in the general area of CSCW have been picked up with success outside of the realm of work seduces Brown and Barkhuus to a similar non sequitur:

Leisure is also something that increasingly makes use of CSCW-type technologies. As the sociality of online activity shows, many [of] CSCW's technologies have had much more success outside the workplace than within. Collaborative virtual environments [...], for example, although seldom used in the workplace, have blossomed into one of the most popular uses of computers in the form of massive multiplayer online games (Brown and Barkhuus 2007, p. 2, emphasis added).

How can the fact that a technology such as collaborative virtual environments (not surprisingly) turned out to be not particularly useful in cooperative work settings but (not surprisingly) has fared much better in an entirely different domain be an argument for CSCW to shift its focus away from work or for that matter 'move into studying leisure, entertainment and pleasure'? CSCW's concepts and ways of doing socio-technical research have influenced many neighboring research areas, from HCI to STS to distributed computing. Why should its success make the field dilute its program?

Unusually muddled thinking seems be at work in the call for shifting the focus of CSCW away from work. This becomes evident if we, just for a minute, 
consider other technologies than the ones mentioned by Crabtree, Rodden, and Benford. When we do so, we will easily realize that a vast variety of other technologies exists, in various stages of maturity, that (potentially) are of equal relevance to $\mathrm{CSCW}$. Let me just point to high-level computational notations for 'business process modelling' (e.g., BPEL), computational 'ontologies', peer-to-peer protocols, 'service-oriented architectures' (SOA), robotics, space-based architectures ('data grid' technology), 'bigraphical reactive systems', 'XML spaces', and so on. In fact, no kind of information technology is, in principle, without actual or potential relevance to CSCW. Given the endless variety of technologies of potential interest to $\mathrm{CSCW}$, it would be futile for $\mathrm{CSCW}$ to shift its focus in response to new technologies. In short, their argument for moving away from work is confused.

\section{The concept of 'work'}

Concepts lead us to make investigations. They are the expression of our interest and direct our interest. Wittgenstein (1945-46, § 570)

Having come this far, it is time to address the question: what do we mean when we discuss whether or not CSCW should move its 'focus away from work'? Indeed, what does the term 'work' mean? Does 'work' only refer to 'industrial work' or similar (putatively) highly routinized forms of work; or more generally, to 'wage work' or 'paid work'? What about 'domestic' activities? Isn't it 'hard work' to raise a bunch of children, making sure they are reasonably clean, eat healthy food, and in general behave well? Isn't 'work', as we've known it, undergoing radical change these years? Aren't the boundaries between 'work' and 'leisure' and 'domestic life' in flux? Don't people check their email and bank accounts and update their Facebook profiles while 'at work'? And on the other hand, don't they, while 'at home', intersperse their 'domestic' or 'leisure' activities with activities related to 'work'? What about the activities patients in hospitals and customers in supermarkets are expected to do? Isn't that 'work' too? Not to forget 'home work'! Or 'voluntary work' in local soup kitchens or remote disaster areas? What does the term 'work' mean anyway? Isn't the term 'work' in any event being used in all sorts of ways? And while the term 'work' is of course used in familiar combinations such as 'paid work', 'farm work', 'industrial work, 'construction work', 'paper work', 'field work', etc., don't sociologists also use the term in more exotic ways, such as, for instance, when they talk about 'face work' (Goffman 1955; 1959), 'articulation work' (Strauss 1985), 'demeanor work' (Randall and Hughes 1995; Martin and Rouncefield 2003), etc.?

The concept of 'work' is a cornerstone concept for CSCW in that it, nominally at least, plays a key role in defining the scope of the field. Whether or not the 
appearance of the word 'work' in the name of the field is of significance, or something that now should be dispensed with (or tacitly ignored), is of course what is under debate. But in order to establish whether or not there are reasons for retaining CSCW's focus on work, a clarification of the concept of 'work' is of course a prerequisite: How could we otherwise establish what it would mean and imply to retain the focus on work or to move it or widen it?

There is an additional reason for devoting en entire section to an analysis of the concept of 'work'. It is often suggested that, since the term 'work' is being used in some sociological literature in a rather special sense, then 'work' in that rather special sense can be used for defining the scope and focus of CSCW as well. For instance, in their important book on Fieldwork for Design, Dave Randall, Richard Harper, and Mark Rouncefield make the following remarks in the context of discussing the role of fieldwork and ethnomethodologically-informed ethnography in CSCW:

There has been considerable discussion of the nature of cooperation in work settings and one stance on this has been that the phenomenon of interest must be limited to a fairly narrow sense of cooperation which implies attention to the kinds of dependency that are necessary for the completion of work tasks (Schmidt 1991).

We prefer the initial and foundational assumption of ethnomethodology that work is anything done in order that a social activity is accomplished, and moreover that such work has a processual character. That it, that it is sequentially organised. (Randall et al. 2007, pp. 56f.).

That is, the authors recommend that CSCW's 'phenomenon of interest' should not be cooperative work in the sense of interdependent but distributed activities (as proposed in Schmidt 1991) but rather 'anything done in order that a social activity is accomplished', i.e., what in the ethnomethodological literature is often termed 'socially organized activities'.

This line of reasoning has been taken further, much further, in the previously quoted paper by Crabtree et al. (from 2009), in as much as it is now argued that the ethnomethodologically-informed ethnographic studies of cooperative work settings are not at all about ordinary work:

it is important to understand that the analytic practices employed in ethnomethodologically-informed ethnography were not developed to study the workplace. Rather, they were developed to study the situated practices through which action and interaction is organized by the parties to it wherever it is done. [...] The association of ethnography with the workplace reflects an old misunderstanding of what the notion of "work" in this kind of ethnographic study means. The notion is derived from ethnomethodology and refers to the interactional work through which people organize a setting's activities. (Crabtree et al. 2009, pp. 880f.) 
That is, we are now told that 'work' in the ordinary sense was never the focus of (at least) ethnomethodologically informed ethnographic studies in CSCW. The ethnomethodologically informed ethnographic studies of work that have been published in CSCW for the last 20 years (such as the classic studies of air-traffic control work and the London Underground control room) were not really about ordinary cooperative work at all! The CSCW community has got it all wrong! These studies, we are now told, were rather about 'the interactional work through which people organize a setting's activities', 'wherever it is done'.

Having thus emptied the concept of 'work' of its ordinary meaning and retroactively made $\mathrm{CSCW}$ an esoteric outgrowth of the philosophy of sociology, the authors feel free to argue that 'the analytic practices of ethnography in the workplace' are not 'different to the analytic practices of ethnography in, for example, the home or the museum' (as quoted above). The revisionist historiography is of course intended to legitimize exactly this. But instead of simply saying 'We no longer want to study ordinary work settings and prefer to just do ethnomethodological studies of whatever, wherever', the concept of 'work' as it has been used in CSCW for a couple of decades now has to be redefined and the body of workplace studies that form an important part of CSCW's legacy has to be reinterpreted.

Anyway, it is not clear which of the different uses of the term 'work' in ethnomethodology is being invoked when it is contended that the 'initial and foundational assumption of ethnomethodology [is] that work is anything done in order that $a$ social activity is accomplished' or that 'the notion of "work" [...] refers to the interactional work through which people organize a setting's activities' 'wherever it is done'. One would think that what is alluded to is the term 'work' as used in the 'ethnomethodological studies of work' research program, launched in 1972, where 'work' means ordinary work and in particular specialized domains of skilled activity, typically occupational practices, defined by mastery of sophisticated technicalities (Heritage 1984, pp. $293 \mathrm{ff}$.; Lynch 1985, pp. 6-10; Garfinkel 1986; Sharrock and Anderson 1986, pp. 80ff.). Paradigmatic exemplars of this research program include David Sudnow's study of jazz improvisation (1978), Michael Lynch's study of laboratory work (1985), and Eric Livingston's study of the work of mathematicians (1986). In the words of Lynch, 'These studies are distinguished by their attempts to situate themselves in the settings they describe. Garfinkel's maxim of the "unique adequacy" of methods locates a concern in these studies to operate from within the competence systems they describe' (Lynch 1985, p. 6). Thus, a reference to the notion of 'work' in the 'ethnomethodological studies of work' research program would not make sense in an argument for a concept of 'work' as 'anything done in order that $a$ social activity is accomplished' or 'the interactional work through which people organize a setting's activities', 'wherever it is done'.

Now, in some ethnomethodological writings the term 'work' is indeed being used, in this peculiar and highly abstract sense, to denote what members do to 
'sustain social order' (Turner 1974), for instance the 'recognition work' involved in 'doing walking as a members' accomplishment' and members' ability to 'distinguish between "walking-together" or "walking-alone" (Ryave and Schenkein 1974). This usage seems to have been derived from how the term is used in conversation analysis. Harvey Sacks would for example assert that it requires 'work' to 'be an ordinary person'. Similarly, he asserts that it involves 'work' to 'only' 'see and report the usual aspects of any possibly usual scene' (Sacks 1970, p. 218), just as he, in another context, would use expressions like 'the work of understanding the talk of others' (Moerman and Sacks 1971, p. 182). This use of the term 'work' is certainly not common, to say the least. Does it make sense to say that it requires 'work' to 'only' 'see and report the usual aspects of any possibly usual scene' or to talk of 'the work of understanding the talk of others'? And if so, which? And what would be the implications of substituting this usage for the ordinary concept of 'work' that originally defined CSCW's scope? Since those who advocate (or rather 'prefer' or simply stipulate) this substitution have not done the work of addressing this issue, it needs to be done here. First, though, a modicum of conceptual analysis is called for.

\subsection{Stuck within ordinary language}

It would be tempting to simply stipulate a definition of 'work' but that would just raise a chorus of objections saying 'Why do you draw the boundary here and not there?' and so on. And rightly so. Without criteria, such a stipulation would be arbitrary.

The concept of 'work' is a concept from ordinary language. We therefore have to examine how 'work' is ordinarily understood and used. This may be seen as controversial, for-really! - how can respectable scholarly work possibly rely on something that is, or so they say, as notoriously woolly and loose as ordinary language, the language of butchers and bus drivers?

There are two reasons for this. What is at stake here is more than a word (a phonetic pattern); what is at stake is a concept and the distinctions in the making of which it is applied. John Austin expressed it nicely:

words are our tools, and, as a minimum, we should use clean tools: we should know what we mean and what we do not, and we must forearm ourselves against the traps that language sets us. [Our] common stock of words embodies all the distinctions men have found worth drawing, and the connexions they have found worth making, in the lifetimes of many generations: these surely have stood up to the long test of the survival of the fittest, and more subtle, at least in all ordinary and reasonably practical matters, than any of you or I are likely to think up in our armchairs of an afternoon - the more favored alternative method. (Austin 1956-57, p. 181f.)

The second reason is related to the first one: if the issues motivating the research are formulated in terms of ordinary language, then the articulation of the 
findings of the research cannot escape ordinary language. Of course, in many scientific areas the phenomena under investigation are not identified or determined in terms of ordinary language: quarks and quasars, mitochondrial membranes and transfinite numbers. In other areas, however, the cornerstone concepts are ordinary language concepts. Here there is no escape from the conceptual schemes of ordinary language. As observed by Hannah Pitkin in her cogent (Wittgensteinian) analysis of the grammar the concepts such as 'power' and 'influence' in political science:

a "purely observational" social science independent of our existing conceptual system in the realm of action might or might not be possible, might or might not be interesting or useful; but it could not tell us the things we now want to know about society and politics. It could not answer the questions we can formulate, for they are formulated in the concepts we have (Pitkin 1972, p. 274).

In practice, she adds, 'what social scientists do is not, of course, any conceptfree observation of events among human beings, but an attempt to fiddle with the concepts we already have in such a way as to make the scientifically usable'. This has meant, inter alia, 'the use of 'operational definitions' and the attempt to redefine familiar concepts [e.g., 'power'] in such a way as to make them realistic, factual, or scientific'. However, 'if our operational definition of "power" is not related to the meaning of "power" then the results of any study we conduct with it will not yield information about power' (pp. 274f.).

Similar problems obtain when attempts are made to transform ordinary psychological concepts such as 'consciousness', 'intelligence', 'thinking', etc. into technical concepts. One can of course stipulate a precise definition for 'consciousness', 'intelligence', 'thinking', etc., but then it is close to impossible to account for the relationship between the research question, as rigorously defined, and the findings expressed in terms of ordinary language or in language that is inseparable from ordinary language. As suggested by Graham Button et al. (1995), 'cognitive science' got into deep trouble due to precisely this murky relationship between the conception of the problem (e.g., the nature of 'thinking'), the conception of the research (e.g., 'recursive function theory'), and the conception of the research results as interpreted in prose (e.g., 'machine thinking'). The results may have been technically sound, considered as a highly flexible form of computational system, but it did not 'yield information' about thinking, to put it that way.

Like concepts such as 'power' and 'thinking', the concept of 'work' is not a technical term; it belongs to ordinary language. That is, as far as CSCW is concerned, there is no escaping the everyday use of the term 'work': we somehow have to relate to how 'work' is ordinarily used.

$\mathrm{CSCW}$ is not the only or the first intellectual movement faced with this kind of conceptual muddle. Conceptual muddles may erupt when scientific, technological, 
or socioeconomic upheavals shatter established conceptual schemes and practitioners suddenly scuttle to regain firm ground. In the words of Peter Hacker:

Each new intellectual advance, such as the invention of non-Euclidean geometries, of new logical calculi, of Gödel's incompleteness theorem, of intuitionistic mathematics and so forth, illuminates new domains of thought, but also casts long shadows across our conceptual scheme. New theories and discoveries in science, such as relativity theory, quantum mechanics, molecular biology and neurophysiological psychology reverberate throughout our intellectual framework, shaking elements loose from their scaffolding, introducing new concepts the articulations of which with pre-existing concepts and conceptual structures cannot easily be apprehended. (Hacker 1996a, p. 272)

Hacker adds that 'Advances in technology, such as computer science and cybernetics, mesmerize us, and lead us astray.' The massive confusion concerning the notions 'information', 'computation', 'cognition', 'intelligence', 'language', etc. bear ample witness to this observation. Conceptual muddles may also develop when different domains of discourse that have heretofore coexisted peacefully in their separate habitats suddenly, for some reason, are thrown together, as it for instance happens when it is realized that scientific, technological, or practical problems require the concerted effort of previously unconnected disciplines and professions. CSCW is a prime example of such a field and the bewilderment this may engender, witness the troubles centering on notions such as 'plans and situated action', 'practice', 'knowledge', 'awareness', 'cooperation', etc., not to mention 'shared understanding', 'shared knowledge', and so on. The concept of 'work' is a case in point.

Philosophy has, perhaps, been more severely afflicted by conceptual confusion than other areas of scholarly work, but it is also in philosophy that we find sophisticated methods for handling such afflictions. In particular Wittgenstein, but also Gilbert Ryle, John Austin, Alan White, and others, developed methodical approaches to conceptual analysis to do exactly that kind of work and since the 'diseases' for which they were developing their 'therapies' are not at all confined to philosophy, the usefulness of their approaches is not restricted to philosophy's internal affairs either.

There are additional reasons why especially Wittgenstein's investigations is relevant for us in the face of the confusions we have to deal with. As Ian Hacking points out, Wittgenstein has a very special place in modern philosophy:

British philosophy was moribund from Hume to Russell; no matter how much we fancy Reid or Mill or Whewell, there is no Kant, Hegel, Marx, Schopenhauer, Nietzsche. [...] It is as if the travail of the German philosophers, which the English and Americans were never able to endure, was abstracted by this troubled man who was never at home in either culture. 
He took our [Anglophone] philosophy hurriedly across many of the painful transformations that had been worked out elsewhere. (Hacking 1975, p. 176).

It may be argued, though, that mainstream Anglophone philosophy since then has moved off in quite different directions and that Wittgenstein's philosophy has been surpassed, especially in American philosophy. However, what may look like a progress is more accurately described as a continuation of the earlier conceptions promulgated a century ago, by the young Wittgenstein in the Tractatus (from 1921) and by the Vienna Circle (Schlick, Neurath, Carnap), but has since then been demolished by Wittgenstein: 'although the central contentions of the Tractatus were explicitly disowned by the older Wittgenstein, the seeds sown by his younger self and fostered by the logical positivists [of the Vienna Circle], sprouted afresh. In the late 1960s and throughout the 1970s a second generation of philosophers flooded the marketplace with ideas explicitly or tacitly harvested from the fields of the Tractatus and the logical positivists' (Baker and Hacker 1984, p. 4). By the mid-1980s 'it was evident that in many respects the spirit of the Tractatus, merged with the scientific and occasionally scientistic character of post-positivist ideas derived in part from members of the Circle, had triumphed over the spirit of the Investigations and its Oxonian offspring [e.g., the work of Austin and Ryle]' (Hacker 1996a, p. 1). In short, what may seem like progress is actually a regression. Wittgenstein may have taken Anglophone philosophy 'hurriedly across many of the painful transformations that had been worked out elsewhere', but sometimes a therapy cannot be hurried.

So, although Wittgenstein in his later works demolished his earlier conception, his 'powerful arguments' have either passed unnoticed in much of Anglophone philosophy or have been misrepresented or misunderstood; the upshot is that his arguments remain 'as yet unrefuted' (Hacker 1996a, p. 271). Wittgenstein's conceptual investigations remain — not the last word, but the baseline. That alone is enough to learn from his conceptual investigations in trying to find our way out; but it is even more relevant in view of the strong influence post-positivist ideas have had and still have in HCI and CSCW. It therefore seems proper to preface the analysis of the use of the concept of 'work' in ordinary language with a hasty paraphrase and interpretation of Wittgenstein's thoughts on the conceptual schemes of our everyday language.

\subsection{The multifaceted notion of 'concept'}

What makes conceptual analysis a somewhat tricky intellectual exercise is that we tend to expect that we have to apply concepts in a manner akin to when the toddler is playing with his beloved 'sorting box': by putting brightly colored blocks of different shape (cube, cylinder, prism...) into differently shaped holes in the box (square, circle, triangle...): 'the red cube fits there and the blue prism there, and not the other way around'. However, our conceptual schemes are not 'sorting boxes'. 
In our various social practices, or 'forms of life', we regularly identify phenomena as being of the same kind or of a different kind, according to some criteria, and we regularly do so routinely and unproblematically, without a fuss. These distinctions, our notions of what is taken as 'the same' and 'not the same', in short, our 'concepts', are interwoven in our non-linguistic as well as in our linguistic practices (Savigny 1998). They are institutions. And, being institutions, our concepts are enormously variegated. There are, as Wittgenstein reminds us, 'countless' 'kinds of sentence', 'countless different kinds of use of all the things we call "signs", "words", "sentences". And this diversity is not something fixed, given once for all; but new types of language, new language-games, as we may say, come into existence, and others become obsolete and get forgotten.' (Wittgenstein 1945$46, \S 23$ ). Our concepts are enormously variegated not only in what they are used for but also in how they are bounded and interrelated.

In the context of this discussion (in the Philosophical Investigations), Wittgenstein introduces the notion of 'family resemblance', to remind us that the phenomena for which we use a particular concept need not have one thing in common in virtue of which we use the same word for all instances (1945-46, $\S \S$ 65-80). - Here one might be tempted to exclaim, 'Could we just settle for that, instruct that the record show that "work" is a "family resemblance" concept, and get back to work (or go home)?' Unfortunately not. The notion of 'family resemblance' concepts is not unproblematic, nor is it regarded as such. As Robert Fogelin puts it, 'the notion of family resemblance is peculiarly susceptible to abuse' and should therefore 'be used circumspectly' (Fogelin 1987, p. 136). Or as Baker and Hacker express it in their Analytical Commentary on Wittgenstein's Philosophical Investigations, the conception of 'family resemblance' is 'controversial' and 'not altogether clear' (Baker and Hacker 2005, pp. 219, 226). Or in the words of Hans Sluga: 'The notion of family resemblance is more problematic than Wittgenstein allows for and that is one reason why it cannot serve as grounding for a comprehensive theory of general terms' (Sluga 2006, p. 14). So, a few additional remarks are called for. And while it may look like a digression, the discussion will be of use for the purpose of clarifying the concept of 'work' for CSCW purposes.

The context in which the notion of 'family resemblance' is introduced is as follows. In $\S$ 1-64 of the Philosophical Investigations (1945-46), Wittgenstein has been dismantling the 'Augustinian conception' of language underlying much of philosophy, including his own in the Tractatus. It can (crudely) be characterized as predicated on the notion that words are names of objects and that language use essentially consists in the expression of propositions of the form: it is thus-and-so. Some 25 years later, in his effort to show the incoherence of this conception, Wittgenstein introduces the construct of 'language-games' $(1945-46, \S 2)$ and uses it as an effective tool to demonstrate that language use, as an integral aspect of our various practices, is enormously more variegated than assumed by the Augustinian conception (e.g., $\S \S 7,23$ ). 
Now, in $\S 65$, Wittgenstein's interlocutor complains that Wittgenstein has not clarified the concept of language-game: 'You make things easy for yourself! You talk about all sorts of language-games, but have nowhere said what is essential to a language-game, and so to language: what is common to all these activities, and makes them into language or parts of language'. To this challenge Wittgenstein replies: 'And this is true.- Instead of pointing out something common to all that we call language, I'm saying that these phenomena have no one thing in common in virtue of which we use the same word for all but there are many different kinds of affinity between them. And on account of this affinity, or these affinities, we call them all "languages". I'll try to explain this.' (§ 65). He then goes on to describe different kinds of 'game' (Spiel):

Consider, for example, the activities that we call "games". I mean boardgames, card-games, ball-games, athletic games, and so on. What is common to them all?-Don't say: "They must have something in common, or they would not be called 'games"'-but look and see whether there is anything common to all.-For if you look at them, you won't see something that is common to all, but similarities, affinities, and a whole series of them at that. To repeat: don't think but look! - Look for example, at board-games, with their various affinities. Now pass to card-games; here you find many correspondences with the first group, but many common features drop out, and others appear. When we pass next to ball-games, much that is common is retained, but much is lost. $(\S 66)$

The argument continues for another dozen of lines until he concludes that 'the upshot of these considerations is' that 'We see a complicated network of similarities overlapping and criss-crossing: similarities in the large and in the small' (§ 66):

I can think of no better expression to characterize these similarities than "family resemblances"; for the various resemblances between members of a family - build, features, colour of eyes, gait, temperament, and so on and so forth-overlap and criss-cross in the same way.-And I shall say: "games" form a family.

And likewise the kinds of number, for example, form a family. Why do we call something a "number"? Well, perhaps because it has a-directaffinity with several things that have hitherto been called "number"; and this can be said to give it an indirect affinity with other things that we also call "numbers". And we extend our concept of number, as in spinning a thread we twist fibre on fibre. And the strength of the thread resides not in the fact that some one thread runs through its whole length, but in the overlapping of many fibres. (§ 67)

This has (needless to say) been read as a conception of general terms, indeed as the 'solution' to the age-old metaphysical 'problem of universals' 
(Bambrough 1961-62). But in that role the notion of 'family resemblance' concepts is hardly satisfactory, not to mention a 'solution'. For taken as a conception of general terms, it does not address the issue that all kinds of similarities can be found beyond those that have been enumerated (e.g., Wennerberg 1967). The problems are, as Bernd Prien puts it, 'very obvious'. With a bit of ingenuity in the art of playing with words everything can be made to resemble anything else. "Any object is in some way similar to any other' (Prien 2004, p. 16). So, what are the criteria of 'similarity'? And furthermore, a family is not defined by similarities of appearance but by kinship; similarity may be a symptom of kinship, but certainly not a criterion (Wennerberg 1967; Prien 2004; Sluga 2006).

However, Wittgenstein is not promulgating a conception of 'general terms', not to mention a 'theory'. And even less is he trying to develop a 'solution' to the 'problem of universals'. He is not in the business of building a new and better sorting box. He introduces the notion of 'family resemblance' as a 'defensive' move, for a 'negative purpose' (Baker and Hacker 2005, pp. 214, 219), deployed 'not in order to justify a general theory but in order to bolster the argument' (Sluga 2006, pp. 2-5). As Fogelin puts it, the notion of 'family resemblance' concepts has two 'chief virtues'. On one hand, it 'helps dispel the commitment to definiteness of sense by exhibiting a set of concepts that violate this standard but are still perfectly serviceable'. And on the other, it leads us 'to abandon the idea that definitions, of the standard kind, are always possible and [...] actually necessary for the systematic development of a subject area' (Fogelin 1987, p. 138). So, instead of taking Wittgenstein's notion of 'family resemblance' as a license to indulge in conceptual anarchism, we should follow his advice: look and see!

The point of Wittgenstein's notion of 'family resemblance' is to stress the open-endedness of our concepts: On one hand, concepts may be open-ended in the sense that they, at some time in the future, may be extended for some reason that we have not anticipated; on the other, concepts may be open-ended in the sense that 'the range of relevant similarities is not fully developed' (Sluga 2006, p. 18). In any event, our concepts are not secured against every possible contingency or ambiguity, for the mere logical possibility of ambiguity or doubt carries no weight. One needs 'grounds for doubt'; 'One doubts on specific grounds' (Wittgenstein 1949-51, §§ 122f., 458):

it belongs to the logic of our scientific investigations that certain things are in deed not doubted.

But it is not thereby just so that we cannot investigate everything and for that reason perforce have to be content with assumption. If I want the door to turn, the hinges must stay put.

My life consists in my being content to accept many things. (Wittgenstein 194951, §§ 342-344.- -Translation adjusted). 
There may be instances that we have not come across or noticed yet in our use of a particular concept but which later make us raise doubt about the boundary: 'Is $k$ really an instance of $K$ ? Should we just ignore it as a borderline-case, or should we rearrange our scheme to accommodate it?' And there is no guarantee that we will not, at some point in the future, find it convenient or even vital to extend or reconfigure the conceptual scheme.

The reason why the notion of 'family resemblance' may come across as philosophically unsatisfactory is, most likely, that Wittgenstein in fact 'did not mean to give a philosophical answer to the question posed by the interlocutor' (Prien 2004, p. 21). His interlocutor is demanding that he produce a definition of the 'essence' of language, i.e., what is essential to this concept: that which all these phenomena have in common and thus makes them instances of that concept, expecting to get an equally metaphysical answer. But at this stage in his Investigations, Wittgenstein has already shown that the conception from which this demand is made is incoherent. So instead of giving the expected reply, he sticks to his overall strategy of bringing the discussion 'home' to the use of language in everyday practices: 'What we do is to bring words back from their metaphysical to their everyday use' (Wittgenstein 1945-46, § 116). His reply to the interlocutor is therefore not 'philosophical' but empirical: he points to how terms are actually used in our ordinary lives and how our conceptual schemes actually evolve. He rejects what could be called the metaphysical frame of discourse: 'Don't say: "They must have something in common, or they would not be called 'games"'-but look and see whether there is anything common to all.' (§ 66). And what he, in effect, shows us in his work is a picture of our conceptual schemes that is even more diverse than suggested by the notion of 'family resemblance'.

First, not all concepts are characterized by 'overlapping and criss-crossing similarities'. While the meaning of ordinary language concepts such as 'games' may be determined by paradigmatic cases and may have blurred boundaries, other concepts such as 'rational numbers', 'complex numbers', 'cardinal numbers' etc. are rigorously defined, viz., by different calculi, and have sharp boundaries. But whereas each of the specific number concepts ('rational numbers', etc.) is rigorously defined, the general concept of 'number' is not. As Wittgenstein expresses it in a manuscript written in the early 1930s:

We consider the cardinal numbers, the rational numbers, the irrational numbers, and complex numbers as numbers; whether we call still other constructions numbers because of their similarity with these, or wish to draw a definitive boundary here or elsewhere, is up to us. [...] In contrast, we call the concept of cardinal number $[1, \xi, \xi+1]$ rigorously bounded, i.e., it is a 'concept' in a different sense of the word. (Wittgenstein 1931-34, § I:70).

That is, the concept of 'number' is a concept in a different sense than that of the concept of 'rational numbers'. The concept of 'number' is a 'family 
resemblance' concept but the specific number concepts ('rational numbers', etc.) are not.

In addition, it is not a criterion of 'family resemblance' that it is difficult to draw a sharp boundary. If we take, for example, color concepts, they are clearly without sharp boundaries. But color concepts are not 'family resemblance' concepts at all, for here the very idea of similarity cannot even find foothold:

Should you say that we use the word "blue" both for light blue and dark blue because there is a similarity between them? If you were asked "Why do you call this 'blue' also?", you would say "Because this is blue, too". [...] Now what should we answer to the question "What do light blue and dark blue have in common?"? At first sight the answer seems obvious: "They are both shades of blue". But this is really a tautology. So let us ask "What do these colours I am point to have in common?" [...] The answer to this really ought to be "I don't know what game you are playing". And it depends upon this game whether I should say they had anything in common, and what I should say they had in common. (Wittgenstein 1934-35, pp. 133f.) ${ }^{7}$

And in fact, color concepts are not and probably cannot be formally defined; rather, they are explained by ostension, as we do when we say 'red:: a color at the end of the spectrum next to orange and opposite violet, as of blood, fire, or rubies'. Color terms belong to an unordered array of 'basic' terms such as 'round', 'hot' and 'cold', 'tall' and 'small' that are all explained by ostension (Sluga 2006, pp. 3f.).

On Wittgenstein's view, then, not all concepts are 'family resemblance' concepts. What we have is rather a motley of conceptual schemes: not just 'family resemblance' concepts ('game', 'language', 'proposition') but also the rigorous concepts of mathematics, physics, chemistry, etc., and the meticulously constructed formal concepts of evolutionary biology and medicine (nomenclatures, classification systems) and an assortment of basic concepts such as 'red' and blue', 'here' and 'there', 'tall' and 'small'. And so on.

Wittgenstein suggests a wonderful picture that may be helpful here: 'Our language can be regarded as an ancient city: a maze of little streets and squares, of old and new houses, of houses with extensions from various periods, and all this surrounded by a multitude of new suburbs with straight and regular streets and uniform houses.' (Wittgenstein 1945-46, § 18).- There is the medieval city with its web of winding streets, which has evolved over centuries in a process of distributed decision-making, and over there are the new parts of town designed by the urban planning office, the 'suburbs' of 'the symbolism of chemistry and the notation of the infinitesimal calculus' ( $\$ 18)$. That is, there are the labyrinthine domains of ordinary language but also domains with strictly defined and bounded concepts.

The 'ancient city' picture is quite appropriate, in that it suggests a historical perspective: our conceptual system has developed over time and remains open to 
development. For example, the concept of 'number' has developed historically by successive extensions (natural numbers, integers, rational numbers, complex numbers, cardinal numbers, etc.). Concepts are extended in a historical process but in different ways: by relaxation of required characteristics (as in the development of number concepts), by affinity (discovery of shared origin, kinship), by similarity (with a unordered cluster of paradigmatic cases, e.g., games), by analogy, and so on. Conceptual schemes are also, in addition to their being extended (in different ways), amended and rearranged. If I may use Wittgenstein's 'ancient city' simile just one more time, boulevards have been cut through the medieval city, reconfiguring the overall geography of the old town and dividing it into separate, perhaps renovated, neighborhoods. Thus, in the course of the development of knowledge in specific domains, entire conceptual schemes are sometimes found in need of rearrangement, and as a result systematic classification schemes are imposed on received conceptual schemes. This happens, for instance, in the development of the systems of biological classification and naming. In such cases, the rearrangement has become the business of entire disciplines (e.g., 'systematic zoology'), complete with professional societies, journals, textbooks, standardization committees, and official nomenclatures and taxonomies.

An important point to take away from this is that concepts are sometimes, perhaps mostly, extended because there are good reasons for doing so, but sometimes it is decided that it would be awkward to extend the concept, for instance because it might lead to misunderstandings: 'Does it make sense to say that gladiator combats are games? What about wars, then? Could one then say: "Don't get violent, it's just a game!'?'-And sometimes concepts have been extended because it seemed like a good idea at the time, and only later does it turn out to be a cause of confusion. That is, what may look like a loosely bounded concept (e.g., a 'family resemblance' concept) may in fact, in actual use, be a set of categorically different concepts that only have superficial similarities.

This issue is of some relevance to the matter at hand, the concept of 'work'. In his elaborate discussion of the grammars of our ordinary concepts (e.g., ordinary psychological concepts), Wittgenstein is adamant to point out that 'similarities' are sometimes frivolous or 'inessential'. Two examples will suffice to illustrate the issue:

(1) In his analysis of psychological concepts Wittgenstein discusses questions such as 'Can a machine "think"?' and 'Can a doll "feel pain"?' Having asserted as a general feature of psychological terms that 'only of a living human being and what resembles (behaves like) a living human being can one say: it has sensations; it sees; is blind; hears; is deaf; is conscious or unconscious' (Wittgenstein 1945-46, § 281), Wittgenstein is met with his interlocutor's objection: "But in a fairy tale a pot too can see and hear!". In a parenthesis, as if lowering his voice to make a snide remark, Wittgenstein 
grumbles: 'Certainly; but it can also talk'. But other than that, he explicitly refrains from saying that such talk is 'nonsense'. Instead he asks, rhetorically: 'Is it untrue or nonsensical to say that a pot talks? Does one have a clear idea of the circumstances in which we'd say of a pot that it talked?' Interjecting for clarification that 'Even a nonsense poem is not nonsense in the same way as the babble of a baby', he then says: 'We do indeed say of an inanimate thing that is in pain: when playing with dolls, for example. Imagine a case in which people said only of inanimate things that they are in pain; pitied only dolls!' (§ 282). The point is that if 'people said only of inanimate things that they are in pain', then they would be having an entirely different concept of pain. However, when we 'say of an inanimate thing that is in pain', then we are using the words 'being in pain' in a sense that is parasitic on the ordinary use of the words: "Here one might speak of a "primary" and "secondary" meaning of a word. Only someone for whom the word has the former meaning uses it in the latter' (§ 276).

Wittgenstein touches upon this issue again a little later by addressing the question 'Could a machine think?' He retorts: 'Could it be in pain?' (§ 349), and then goes on: 'But surely a machine cannot think!-Is this an empirical statement? No. We say only of a human being and what is like one that it thinks. We also say it of dolls; and perhaps even of ghosts' (§ 360). To say that a machine 'cannot think' is not an 'empirical' statement but a grammatical one. We say of creatures that live complex social lives that they can 'think' - and we also, when we fantasize, say it of creatures such as pots, dolls, ghosts, and machines that in the fairy tale or ghost story or science fiction saga are equipped with humanoid features and behavior. The point of fairy tales is that the talking pot is a fairy-tale pot; it belongs to another 'province of meaning'. It is from this the story derives its fascination. However, if we, outside of fairy tales and science fiction and ghost stories and any such province of meaning, were to say of pots that they 'feel pain' or of machines that they 'think', then we would be transgressing the grammars of the terms 'feel pain' or 'to think'.

The methodological lesson is that there are domains of discourse in which a given concept is employed in a sense that is 'secondary' to the application of that concept in another, 'primary', domain of discourse (Hacker 1990, pp. 171f.). It should be clear that we here, in the 'parasitic' relationship between a 'primary' and 'secondary' usage, have examples of relationships between concepts that cannot be categorized as 'family resemblance' concepts. The issue is not one of 'similarity'. It is, rather, that the concept in question ('feel pain', 'think') is used in the same sense but in an entirely different illocutionary role: it is an utterance in the context of a fairy tale.

(2) There are cases where the same word is used in distinctly different ways and where the fact that it is the same word that is used in these different ways is coincidental. That is, it is not a case of 'family resemblance', for there is no 
similarity apart from the use of the same sign. Take for instance, the word 'is'. We say 'The rose is red' but also that 'Two times two is four' (Wittgenstein 1945-46, § 558). 'Is'!? The use of the same word here has no import. The copula 'is' in 'The rose is red' cannot be replaced by the identity sign ('='); it is a different concept. Wittgenstein then remarks: 'Now isn't it remarkable that I say that the word "is" is used with two different meanings (as copula and as sign of equality), and wouldn't want to say that its meaning is its use, namely, as copula and as sign of equality?'-One would ordinarily say that the meaning of a word is 'its use' and in this case that its meaning is bounded by its being used both as copula and as sign of equality, but 'One would like to say that these two kinds of use don't yield a single meaning; the union under one head, effected by the same word, is an inessential coincidence' $(\S 561){ }^{8}$ It is simply a linguistic accident that the same sign is used in both cases, just as it is a coincidence that the sign 'bank' is used for certain, sometimes slippery, financial establishments as well as for the sloping land alongside a river, or that the sign 'heart' is used in language-games of certain forms of mortal illness and of love affairs. But, Hacker points out, 'that means that the criteria for sameness and difference of meaning presupposes a distinction between essential and inessential' (Hacker 1996b, p. 386).

At this point we should proceed with caution. A distinction between the 'essential' and the 'inessential' may bring us back to the metaphysics of the sorting box. We should keep in mind what Wittgenstein had reminded of us earlier, namely, that 'there is not always a clear boundary between essential and inessential' ( $§ 63)$. As if to remind us of that again, Wittgenstein then brings in another and quite illuminating analogy: 'Let's think of a similar case in a game: in draughts a king is indicated by putting one piece on top of another. Now won't one say that it's inessential to the game for a king to consist of two pieces?' (Wittgenstein 1945-46, § 562). To which one would answer 'Surely! It's merely a convenience'. Wittgenstein then goes on to ask: 'But how can I decide what is an essential, and what an inessential, coincidental, feature of the notation? Is there some reality lying behind the notation, to which the grammar conforms?' (Wittgenstein 1945-46, § 562). The second question (about a hidden reality) is rhetorical and the answer of course 'No!'. Contrary to what Platonist thinking would have us believe, there is no object 'behind' the notation to which the grammar is answerable and to which one might appeal. But how then decide what is an essential and an inessential rule? To answer that Wittgenstein (in $\S 563$ ) mentions the widespread convention that, to determine who is to play white, one of the players holds a king piece in each of his closed hands while the other chooses one of the two hands, and then asks: 'Will it be counted as part of the role of the king in chess that it is used to draw lots in this way?'. Evidently not! It does not affect the possible moves of the king in the game. Wittgenstein then concludes this entire line of discussion: 'The game, one would like to say, has not only rules but also a point [Witz]' (§ 564).

A point! The rules of the game serve a purpose in our lives. If somebody has learned all the rules of chess and can now move the pieces in perfect compliance 
with the rules but has not understood that it is all about winning, then the poor soul has not understood 'the point' of the game, namely that the rules have to be applied in such a way that one can, at the end, win the match. The 'point' is what we accomplish, what we regularly accomplish, by applying the rules of our conceptual schemes in our practices: in the rule-governed non-linguistic, prelinguistic, and linguistic practices of our various forms of life: playing football, shopping groceries for the weekend, investigating an ecology, engaging in cooperative work. Concepts are not holes in sorting boxes; they have a point. The point of our concepts highlight what we, in our practices, find 'essential': important, pivotal, crucial, critical, decisive, conclusive.

Hence Wittgenstein's sharp conclusion to this discussion: 'Concepts lead us to make investigations. They are the expression of our interest and direct our interest' (Wittgenstein 1945-46, § 570). What is essential and inessential depends on the practical purpose for which we apply these rules.

A joke has a point (or it's a bad joke), and so has a game: the gist, the purpose, the heart of the matter. A concept has a point too, in that there is a point in using this term and not that in this context. Using a particular term 'mediates a transition' to other situations, other language-games, where the same term is regularly used. When we use a particular term we use it with the illocutionary force that comes with having chosen not to use another term and with having chosen one with the momentum given it by its ordinary use, invoking the distinctions and connections that have 'stood up to the long test of the survival of the fittest', as Austin puts it.

Wittgenstein offers no fix-and-ready solution to the philosophical problem of general terms but a method to develop our sentience towards the diverse and dynamic nature of our conceptual schemes, which may help us to avoid the trap of metaphysics (Platonism and nominalism alike), the trap of presuming that a concept, to be of any use in our scientific work and practical lives, must be sharply defined and bounded, once and for all. What we have to do is to look and see.

What does 'work' mean? How is the term regularly used? Let us look and see.

\subsection{The grammar of 'work'}

The game, one would like to say, has not only rules but also a point

Wittgenstein (1945-46, § 564)

In his protracted effort to evict Cartesianism (and Behaviorism) from the philosophy and psychology of thinking, Gilbert Ryle introduced a series of auxiliary or meta-logical concepts and distinctions. They were all introduced in an ad hoc manner as useful tools for his analyses. One of his tools is a class of concepts he calls 'polymorphous concepts'. 
To understand what Ryle is up to with this category, let us briefly follow his argumentation in a short paper on 'Thinking and language' from 1951. When theorizing about thinking we are, he notes, naturally inclined to say what thinking consists of and how these various elements are combined. Since processes like perspiring, digesting, counting, and singing can be broken down into elementary processes, we would expect the same of thinking. 'But this is a mistake', Ryle observes, adding: "There is no general answer to the question "What does thinking consist of?"'. Ryle then, to sustain his argument, switches to the concept of 'work':

If asked "What does working consist of?" we should quickly object that there was no general answer. Some sorts of work are done with some sorts of tools, others with other sorts. But sometimes the same work might be done with alternative tools. Some work does not require tools at all. The dancer uses her limbs, but her limbs are not implements. A headmaster might do his work though deprived of the use of his arms, or his legs or his eyes. Some sorts of work are done with special materials, like string or Carrara marble. But the work might be done with different materials, and some work does not require materials at all. An artist's model need not even be attending to her work. She might be paid for sleeping or playing patience in the studio. There need be no action, inner or overt, performed by the policeman on his beat, which he may not also perform when strolling round the same streets when his work is over. Not all work is for pay; not all work is unpleasant; not all work is tiring. Nothing need be done, thought, or felt by the professional footballer at work that might not be done, thought or felt by the amateur at play. Work is a polymorphous concept. There is nothing which must be going on in one piece of work which need be going on in another. Nothing answers to the general description "what work consists of". None the less, each specific job is describable. The workman can be told what he is to do. The concepts of fighting, trading, playing, housekeeping and farming are also polymorphous concepts, where the concepts of boxing and apple-picking are nearly enough non-polymorphous. (Ryle 1951, pp. 260f.)

For Ryle the concept of working has now done its job and he can turn back to the job at hand: 'The concept of thinking is polymorphous' (p. 261). We leave his inquiry there, for what concerns us here is of course not Ryle's analysis of the concept of 'thinking' but his characterization, in a kind of adjunct line of argument, of the concept of 'working' as a polymorphous concept. Concepts like 'practicing' or 'obeying' are polymorphous in that none of these words indicate some specific activity. In contrast to concepts such as 'singing', the concept of 'working' is polymorphous in the sense that the application of the term 'working' does not imply the performance of any specific activity.

In the words of Alan White, in his concise account of Ryle's philosophy of mind, polymorphous concepts like 'practicing' or 'obeying' indicate the 
relationship of a given activity 'to its circumstances, and thereby signifies what, on this occasion, it is a form of' (White 1967, p. 59). This is an important point, for it shows the connection between the notion of 'polymorphous' concepts and another of Ryle's auxiliary terms, namely, the notion of 'thick description' (196667,1968 ). One may for example observe (watching a video recording, say) a man making curly lines of blue ink on the surface of a sheet of paper. What is he doing? Merely doodling? Practicing his signature? Signing a document, for instance a peace treaty? 'A statesman signing his surname to a peace-treaty is doing much more than inscribe the seven letters of his surname, but he is not doing many or any more things. He is bringing a war to a close by inscribing the seven letters of his surname.' (Ryle 1968, p. 496). To say of a man that he is signing a peace treaty is a 'thick description', relative to a description of his observable behavior. The motions he is going through could be undertaken for all kinds of purposes, in all kinds of circumstances. The thick description describes the activity in terms that are relevant to those concerned. It stresses 'the point' of the game, if you will. ${ }^{9}$

What is implied, then, when we say of a man, for example, that 'he is now working again', or that 'he is working hard', or that 'he has not been working for quite some time', or that 'he is only pretending to be working'? James Urmson, another of Ryle's and Austin's younger colleagues at Oxford, has written a comment on Ryle's remarks on polymorphous concepts in which applies the methodological notion of 'thick descriptions' in some, for our purpose, very cogent remarks on the concept of working:

Working has no strict opposite or contrary; but it is most typically contrasted with recreation and leisure pursuits. One of Ryle's leisure pursuits and recreations is gardening; I should never be surprised to hear that he has spent the afternoon working in his garden. But perhaps I ought to be surprised when I hear this, for if gardening is his recreation how can he be working when he is gardening? Yet in fact it does not ring at all oddly if somebody says that his favourite recreation is working in his garden. However, we should be surprised if a professional philosopher, filling in one of those tiresome statisticians' questionnaires, were to include his hours of gardening in his answer to a question about the number of hours he worked each week; we should be shocked if he were to refuse a legitimate professional call on his time on the ground that he had other pressing work to do, if it emerged that this other pressing work was lawn-mowing; if he can find much time for gardening over a certain period, then for that period he cannot have been very busy. It is clear that only for certain limited purposes can a professional philosopher's gardening be called work, and that for many important purposes it must be contrasted with his work. (Urmson 1970, pp. 260f.)

That is, to categorize a given activity as work involves reference to purpose and circumstance. Just like a man's writing his signature on a piece of paper, 
depending on the situation at hand, may be described as his practicing his signature, authorizing a purchase order, or signing a peace treaty, a man's turning soil with a spade may be described as recreation or as working; it simply depends on the context. That is, without background information, one would not be able to tell from a short video snippet of an activity whether what it depicted was somebody engaged in work or recreation or something completely different (somebody imitating a gardener, say, for purposes of satire or ceremony). In short, the same physical activity (e.g., removing weed from the lawn, pruning the roses) may, in certain situations or discourses, count for working, whereas the same categorization of the same physical activity in another situation or discourse would be considered flippant. In short, saying of a man that he is working is a 'thick description' of his doings: it relates to the circumstances and purposes of his doings: their point.

But why does it 'not ring at all oddly', as Urmson correctly points out, 'if somebody says that his favourite recreation is working in his garden'? Urmson's answer is that certain kinds of activity have such similarities with certain prototypical work activities that they, in limited discourses, are talked of a 'work':

It is also worthy of attention that not all recreation, however strenuously pursued, can be called work. It is all very well in the case of gardening, knitting, carpentry, and rug-making; these are most naturally categorized as working; it is perfectly reasonable to speak of somebody as working on his stamp-collection or on a painting. But we should require some special explanation if we were told that somebody was working on a game of ludo or a detective story, or that he was working at a country walk or a game of cricket. No doubt, if I am writing a detective story, even for fun, I may be said to be working at or on it, but not when I am sprawled in an armchair reading it (Urmson 1970, p. 261).

It is plain that we, in our ordinary discourse, make a distinction between occupations which would be counted as 'work' in all standard contexts and those which would be called 'work' only for some purposes. Dubbing the first ones 'primary cases of work' and the others 'secondary cases of work', Urmson then goes on:

The central among the primary cases of working are those in which one does something, whatever it consists of, because it is necessary or useful in a practical way. Since people typically have the duty to do such things and are frequently paid for doing them, we also extend the primary cases of working to include doing anything, whatever it consists of, if it is done as a matter of duty for pay. In this way the game-playing of the professional comes to be counted as a primary case of work. [...] In the case of primary work we thus have a slide, excluding action-content, from whatever is practically necessary or 
useful, to the same done as a matter of duty for pay, to anything which is done as a matter of duty for pay (Urmson 1970, p. 263).

That is, for an activity to count as working requires more than its unfolding in time and space. The 'primary cases of work' designate activities that are considered 'necessary or useful in a practical way', either in terms of the concrete fruits of the labor (food, clothing, timber, tools, machines) or in terms of some other reward (remuneration, recognition). The point is practical necessity or usefulness: the necessity of having to deal with all sorts of imposed relevances, constraints and requirements, priorities and urgencies, and what flows from that: mastery of technicalities, ability to make do with available resources and to persevere, and so on. Not only that. In a system of social division of labor, constraints and requirements, etc. are typically externally defined, by other parties. Preparing a meal for others, perhaps for paying clients, implies different constraints and requirements and hence different concerns, procedures, and techniques, than preparing a meal for oneself. After all, if you are cooking for yourself, no great harm is done if the sauce is too salty or the steak too 'well done'. It may be frustrating, of course, but is not really serious. Working for oneself may look the same as working in a system of division of labor but the circumstances are different: different issues of practical usefulness and necessity obtain, and thus the criteria of satisfactory outcome are different, the constraints and requirements in terms of planning and timing are different, etc. One could say that working in a system of division of labor is more 'work-like' than working in seclusion for oneself.

The 'secondary cases of work', by contrast, can be considered work because they are also serious affairs in that they too require 'effort and concentration':

Secondary cases of work are those which resemble reasonably closely in action-content typical and common forms of work. One of these, for example, is the cultivation of the soil, and thus the construction of an ornamental rockery for the pleasure of its construction comes to be counted as (secondary) work. Also, since central cases of work typically require effort and concentration, we are even prepared to say of an enthusiastic amateur gameplayer that he is working hard, though we are unlikely to say that he is working simpliciter. It would seem that we will not say that the solver of crossword puzzles is working because he is not doing anything sufficiently similar to what people commonly do in the way of primary work, though we can say that the amateur carpenter is working at his bench without any qualms (Urmson 1970, p. 263).

What Urmson is saying, in effect, is that we would not find it odd to talk of 'working in the garden' even when that pursuit would be considered strictly recreational, because 'working in the garden' anyway has obvious similarities with the work we do for a living. A kind of family resemblance seems to obtain, 
not an unordered one (like 'games') but an ordered one, where the primary cases are considered work, not in virtue of the particular activities involved but in virtue of the circumstances, the context, while the secondary cases are considered work, in particular situations, not in virtue of the circumstances but in virtue of the similarity of the particular activities with prototypical work activities.

In sum, as analyzed by Ryle and Urmson the concept of 'work' is a polymorphous concept. The term 'work' is not used to refer to certain observable activities but rather to express the circumstances under which the activities are performed. The term is primarily used, in ordinary language, to express or emphasize that the given activity serves useful or necessary practical purposes, and that it therefore requires effort and concentration and presumes mastery of all sorts technicalities - and secondly, and in a kind of subordinate role, to designate to activities that, due to their similarity to paradigm cases, also require effort and concentration and presume mastery of all sorts technicalities. The concept of 'work' implies that it is not mere pleasure but serious stuff: activities faced with serious complexities. It is because of this that one can say, as Marx does, that even 'really free working', such as composing music, 'is at the same time the most damned seriousness, the most intense exertion' (Marx 1857-58, p. 499).

In other words, the meaning we impart to an activity by using the term 'working' was expressed succinctly by Johnny Cash in his introduction to the song 'There ain't no easy run', a salute to the work of truckers:

Sixteen forward gears, diesel smoke trailing in the wind.

Eighteen tires checked and singing on the pavement.

Five thousand miles to cover, three weeks away from home.

And it's work, Mister, it demands the best.

And whether your run is on Interstate 70 or hauling freight down the eastern seaboard,

If you're a gearjammer you know there ain't no easy runs. ${ }^{10}$

That is 'the point' of the concept of 'work'. Work demands the best: it typically requires skill and competence, stamina and effort, dedication and attention.

Let us move this a bit further. First a note of caution. When James Urmson talks of 'primary' and 'secondary' cases, he may be alluding to Wittgenstein's use of similar terms in his discussion of the grammars of the concepts of 'feeling pain' and 'thinking', namely, that the 'secondary' usage is parasitic on the 'primary'. If so, this would be mistaken. The notion of 'secondary cases' of work is not based on allegory, that is, using a term in the same sense but in an entirely different discourse, in another 'finite province of meaning'. The 'secondary cases' are rather 'secondary' in that they are 'work' in a derived and marginal sense. Concepts have a point, and in the case of the concept of 'work' the point is that it 
'work demands the best'. Anyway, we can of course also talk about 'primary' and 'secondary' cases in the sense of a gradation from 'central' to 'peripheral', that is, without implying some strict hierarchy of discrete steps. Remember, 'there is not always a clear boundary between essential and inessential' (§ 63).

Central to the concept of 'work' (in the verb form 'to work', 'working') is that work is activity: it has a beginning and an end and thus what Wittgenstein calls 'genuine duration' (Wittgenstein 1945-48). Work is something we do (under certain characteristic circumstances). This takes work apart from 'art', 'skill', etc. that are not used to talk of activities but rather to talk of the ways in which an activity is performed: 'artfully', 'skillfully', or of prerequisite competencies.

On the other hand, 'work' is closely related to the concept of 'practice'; it is something we $d o$. It is an activity concept, but in a special sense. When we talk of 'a practice' we are not talking about a particular activity, but of a species of regularly performed activity (cf. genotype versus phenotype). That is, practices do not have genuine duration. My driving the car ends when I stop the car, kill the engine, and pull the key. My practice of driving does not cease when I park the car or when I go to sleep but is demonstrated in my recurrent driving the car and doing so (more or less) in accordance with the traffic code and the conventions of proper conduct in public spaces. When we talk about 'practice' we are talking about a rule-governed activity. That is, a practice is something one learns and which one thereby eventually masters (or does not master). This makes 'practice' different from related concepts like 'culture', 'custom', 'habit'. One does not master a culture or a custom: one adopts it or is socialized into it, and one certainly does not master one's habits. The concept of 'practice' bridges the conceptual schemes of 'activity', 'skill', 'technique', and 'rule'.

Where 'work' stresses the characteristic circumstances under which the activity is performed, the concept of 'practice' stresses the normative regularity characteristic of a category of activity that may or may not be a work activity. An activity is characterized as 'work' in view of the nature of the circumstances, whereas a 'practice' is characterized by its being rule-governed (in the classical usage, its commitment to 'theory'). A practice is something one can learn to master after hard work, and one can work according to established practices.

We of course also use the term 'work' in ways that are derivative in another sense than the distinction between primary and secondary cases suggested by Urmson. For example, in its noun form the word 'work' is used in all sorts of ways: of designated places of work activities ('coming to work', 'being at work'), of occupation or employment ('looking for work', 'being out of work'), task ('taking work home', 'he's got his work cut out for him'), or the outcome of work activities ('a work of fiction', 'collected works'). This usage is hardly coincidental but rather an often useful way to 'mediate a transition' between different affiliated language-games, in much the same way as we can talk about 'a healthy man', 'a healthy diet', 'a healthy complexion', etc. ${ }^{11}$ There is also a sense in which the term 'work' is being used to emphasize not activity but effect. It thus 
makes sense to ask someone proposing a new technical term, 'What kind of work does it do for you?', meaning of course: 'Is it of any practical use? does it make $a$ difference? does it accomplish anything?'. In this usage the emphasis has shifted from 'work' as a demanding but necessary activity to 'work' as decisive effect: the function of some effort: 'It works for me'. ${ }^{12}$ We use terms in such derivative meanings routinely, normally without getting into trouble.

Not surprisingly, the term 'work' has been appropriated by different specialized disciplines to do, well, all kinds of specialized 'work'. In physics, for instance, 'work' means the expenditure of energy required to cause a state change (a displacement of an object). An abstraction over the notion of work as mere toil, 'work' is here defined as 'force times distance'. Physicists and mechanical engineers normally have no difficultly in distinguishing this concept of 'work' from the concept of the ordinary work in which they daily are engaged. They do not apply the mechanical or the thermo-mechanical concepts of 'work' when they discuss whether a particular project is 'interesting work' or 'hard work' or 'boring work'. Likewise Freud could talk about 'dream work' without falling into the trap of mistaking the work in 'dream work' for the work of those who manufactured his couches and cigars.

As noted above, the term work is also used by sociologists in various specialized combinations ('face work', 'articulation work', 'demeanor work', etc.). These phenomena are dubbed 'work' because they involve specifiable competencies. But it would be misleading to think of these phenomena as necessarily identifiable activities: like 'art' and 'skill' they are rather characterizations of the ways in which logically primary activities are performed. Nobody in his right mind mistakes the sense in which we talk about 'work' when we talk about 'articulation work' for 'work' in the primary sense. The distinction is one that all workers apply and must apply, and they do that when they complain that they have too many meetings or that they are being interrupted in their work by phone calls. It is the distinction workers apply when they say, 'Enough talk, let's get to work!' It is a central concern to all work (in the primary sense). It is the basic tenet, also, of 'the natural attitude'.

While 'at work', that is, while present at 'a work place', a site officially or conventionally devoted to work activities, one may of course undertake all kinds of activities that are unrelated to the work activities for which one's presence is required. One may visit the bathroom or update one's Facebook profile. Relieving oneself in this or that way is not work, although it may require labor. On the other hand, work activities are not necessarily required to take place at designated work places. As argued by Ryle, 'work' is a polymorphous concept; that is, it does not denote specific kinds of activity; but nor does 'work' denote activities performed in specific kinds of location. The concept of 'work' denotes activities carried out under characteristic circumstances. Work activities are typically carried out at designated locations but some may just as well be carried out in the living room of one's home, in the passenger seat of an airplane, or for that matter in the bathroom or on Facebook. 


\section{4. 'Work' in conversation analysis}

As noted in passing earlier, the term 'work' is also used in areas of sociology, in particular conversation analysis, in a rather peculiar way. However, as long as the peculiar usage is limited to a corner of sociological theorizing no great harm is done. But when this usage is then not only transplanted to CSCW but put forward as a cornerstone concept, as a concept defining the scope of the field, then massive confusion results.

Two examples from Sacks will suffice to show the problem. In a famous lecture, Sacks discusses stories people tell, or rather do not tell (1970) ${ }^{13}$ : 'A kind of remarkable thing is how, in ordinary conversation, in reporting some event, people report what we might see not to be what happened, but the ordinariness of what happened.' For example, somebody goes to the beach for the weekend and coming back they say something like: "We went to [the beach]. Bud played golf and I sat around the pool with the girls". The reports do not so much give attributes of the scene, activity, participants but announce the event's ordinariness, its usualness. We might figure that lots of these things could be stories, but they are not made into stories.' This, Sacks says, has left him 'wondering about the non-production of stories' (p. 216). And he then goes on to 'the central sorts of assertions' he wants to make:

Whatever we may think about what it is to be an ordinary person in the world, an initial shift is not to think of an "ordinary person" as some person, but as somebody having as their job, as their constant preoccupation, doing "being ordinary". It's not that somebody is ordinary, it's perhaps that that's what their business is. And it takes work, as any other business does. And if you just extend the analogy of what you obviously think of as work-as whatever it is that takes analytic, intellectual, emotional energy - then you can come to see that all sorts of nominalized things - personal characteristics and the like - are jobs which are done, which took some kind of effort, training, etc. (Sacks 1970, p. 216).

It is worth noticing that Sacks is well aware that he is stretching it, for he makes the effort of pointing out that what he is doing is to "extend the analogy of what you obviously think of as work'. But does it make sense to say that it requires 'work' to 'only' 'see and report the usual aspects of any possibly usual scene'? If so, which?

What Sacks is saying here is that it takes 'some kind of effort, training, etc.', i.e., 'work', for somebody not to do something, namely, not to make events that 'could be stories' 'into stories' This is not only idle speculation; it is incoherent. When we talk about work ('to work', 'working', 'his work') we are referring to an activity (current or pending). Work is an activity and has duration. One can begin working, stop working, resume working, etc., just as one can tell jokes while working. It is a transgression of the boundaries of sense to describe in 
activity terms something that is not done. And even less so does it make sense to talk of such non-activities ('non-production') as 'work'.

In view of the fact that ethnomethodology historically builds on and in critical ways is a continuation of the phenomenological analysis of ordinary practices originally developed by Alfred Schutz (cf., e.g., 1944; 1953), it is here worth pointing out that Sacks' whole analysis in 'Doing "being ordinary"' turns the conception of the 'natural attitude' upside down. What Schutz is arguing is that we, most of the time, in the 'natural attitude' of our daily lives, have to and $d o$ take for granted that things are as they normally are; and if things indeed turn out to be as they normally are, they are routinely not noticed and routinely go unreported. The practitioner in the 'natural attitude' of ordinary working life does not engage in questioning whether something 'ordinary' can be seen or made to look as something out of the ordinary. Does it, for the practitioner in the 'natural attitude', require an effort, not to mention work, to take things for granted? It would not make sense to say so.

It is fair to assume that Sacks perhaps got carried away here, that he drifted into hyperbole to make his students listen and wonder. He did not, after all, publish it himself. That is, it does not subtract from the his contribution to science or his standing as a highly creative thinker, and would only merit a footnote in a scholarly intellectual biography had it not been for the fact that his use of the word 'work' in these, perhaps offhand, remarks now are being offered, surreptitiously, as a substitution for the ordinary concept of 'work' that has hitherto defined CSCW.

On the other hand, it probably was not just hyperbole, for in another context, in a paper written by Sacks in collaboration with Michael Moerman (1971), the term 'work' is again used in a puzzling way. The authors raise the question: 'Why do people understand one another?', but instead of dismissing the question as quasimetaphysical by pointing to the diverse rule-governed non- and pre-linguistic social activities, the 'forms of life', in which linguistic practices are interwoven, the answer suggested by Moerman and Sacks is that the 'work of understanding the talk of others' (p. 181) consists in local, immediate, continual, etc. 'conversational sequencing' (turn-taking, selection of next speaker, etc.):

[Turn-taking systems] work in such a way as to require that parties to a conversation do extensive work of understanding if their system of turn-taking is to operate as it does. Both employ utterance units which need to be constantly monitored for their completion. Both operate to select future speakers in an one utterance at a time fashion. And both, thereby, impose upon conversation participants demanding and identical tasks of understanding and of demonstrating understanding (Moerman and Sacks 1971, p. 185).

That is, the answer to the question 'Why do people understand one another' is that they do so because 'they demonstrate to one another that they understood (or failed to understand) the talk they are party to' (p. 185), turn by turn. ${ }^{14}$ The 
important thing to notice, in the present context, is the peculiar use of the term 'work': that 'turn-taking' requires 'extensive work of understanding'. Again the term 'work' is used is used to refer to some occult cognitive activity, here some putative 'work of understanding' conceived of as a logically necessary and anterior cognitive process.

These examples are, I submit, not merely a couple of faux pas by Sacks but should be seen as intimately related to the foundational assumptions of conversation analysis. What one should understand is that there hardly is room for the ordinary concept of 'work' in conversation analysis, in as much as conversation analysis by methodological choice, ab initio, brackets out the specific circumstances under which utterances are made. It is, as Sacks explicitly states, foundational to conversation analysis that 'conversation is independently organized', that is, organized independently of 'the names, sexes, social statuses, etc., of the parties': 'some part of a sequential organization of a conversation has to do with identities that the conversation itself makes relevant, such that for at least those facets of the conversation one needn't make reference to other sorts of identities that parties have which are, so to speak, exterior to not simply the conversation, but to its sequential organization' (Sacks 1971, pp. 361f.).

This principle is spelled out in his seminal article written together with Emanuel Schegloff and Gail Jefferson:

What we mean to note is that major aspects of the organization of turn-taking are insensitive to such parameters of context, and are, in that sense, "contextfree"; but it remains the case that examination of any particular materials will display the context-free resources of the turn-taking system to be employed, disposed in ways fitted to particulars of context. It is the context-free structure which defines how and where context-sensitivity can be displayed; the particularities of context are exhibited in systematically organized ways and places, and those are shaped by the context-free organization. (Sacks et al. 1974, p. 699).

The authors make perfectly clear that this is a methodological choice:

To begin with, a problem for research on actual conversation is that it is always "situated"-always comes out of, and is part of, some real sets of circumstances of its participants. But there are various reasons why it is undesirable to have to know or characterize such situations for particular conversations in order to investigate them. And the question then becomes: What might be extracted as ordered phenomena from our conversational materials which would not turn out to require reference to one or another aspect of situatedness, identities, particularities of content or context? (Sacks et al. 1974, p. 699)

Conversation analysis adopts as its phenomenon of choice the structure of conversation conceived of strictly as organized independently of 'context'. Such a 
foundational stipulation is legitimate. One can of course investigate rapid contractions of one eye without considering whether such contractions are mere tics or ironic or lewd 'winking'. And one can of course study handwriting irrespective of whether a particular act of longhand inscription is an act of signing a peace treaty or an act of practicing one's signature or testing a new fountain pen. But we just have to keep in mind that conversation analysis research has decided that 'context' has to be displayed in the 'context-free structure' of the conversation. ${ }^{15}$ Or to put it differently, conversation analysis has opted for wafer thin descriptions of social interaction, bracketing by choice not only the identities of the conversationalists, but also and, from a CSCW perspective, in particular the specifics of the organizational setting and the structure and behavior of the artifacts and processes to which workers orient in their work activities. The consequence of this is that what in conversation analysis is called 'work' is not work that has any resemblance with what is ordinarily understood by 'work'. Since the ordinary concept of 'work' is a 'thick description' concept and conversation analysis by foundational edict rules out references to circumstances, there is no place in the conceptual scheme of conversation analysis for the ordinary concept of 'work'. It is as alien there as the concept of friction would be in Euclidian geometry.

What in the writings of conversation analysis, and in ethnomethodological writings influenced by conversation analysis, is called 'work' are not activities categorized as 'work' in virtue of the characteristic circumstances under which they are conducted. In fact, what is called 'work' are not even activities, for the term 'work' is not used in reference of phenomena that have genuine duration. What is described as 'work' are the display of (mundane and almost generic) competencies such as 'understanding the talk of others' or the criteria for discriminating 'walking together'. In some cases what is described as 'work', e.g., the 'non-production' of stories, is the absence of some conceivable action but then it is even dubious if one could call that a phenomenon.

The peculiar concept of 'work' that has been derived from conversation analysis undermines from the outset the conception of the natural attitude. In accordance with this, conversation analysis brackets out the institutional context of the object of their investigations. Just like the cognitivist notions 'plans', 'shared understanding', and 'mental models', the use of this peculiar notion of 'work' in CSCW will tend to deprive phenomena such as professional work practices of their specificity. When put to work in CSCW, it is a conceptual mechanism that makes the phenomenon disappear: what is specific about ordinary work practices performed by professionals in organizational settings, with their massive technicalities, is bracketed out.

Finally, as noted in passing above, it has been suggested that CSCW's 'phenomenon of interest' should be defined in terms of 'socially organized activities' (Randall et al. 2007). This is in fact a position with a long and distinguished career in CSCW, in that John Hughes, Dave Randall, and Dan 
Shapiro in 1991 argued that 'that all of work is-i.e. can helpfully be analysed as - socially organised' and that CSCW, in adopting that analytical stance, should be seen as a 'paradigm change' for computer science as well as for sociology (Hughes et al. 1991). This position has much to say for it, as long as what is being argued is an analytical stance. As a term summarizing ethnomethodology's persistent critique of mainstream sociology's neglect of the ways in which social order is continually produced, the concept of 'socially organized' phenomena (occasions, activities) aptly expresses ethnomethodology's 'study policy' (Sharrock and Anderson 1986). In CSCW the term has been useful as a way to assert and maintain the analytical focus on the myriad ways in which order is produced. However, for the purpose of defining the scope of CSCW's research program, it is far too abstract. What kind of human conduct is not, or cannot be seen as, 'socially organized'? Used as a term to define the scope of CSCW, it simply defines CSCW as a branch of ethnomethodology on par with conversation analysis. If CSCW is to pursue the research program that was, tentatively, formulated 20 years ago and then fleshed out in a string of ethnographic as well as conceptual and technical studies, its efforts must focus on the (typically elaborate) coordinative practices that characterize modern cooperative work settings, while conceiving of them as 'socially organized' phenomena, of course.

\section{3. 'Work': a reality check}

What are the criteria for demarcating CSCW's horizon? By arguing that CSCW has to move in the particular direction they are pointing, Crabtree et al. (2005) seem to employ an implicit criterion that we most definitely need to make explicit and discuss. A closer look at their argumentation will make it clear.

The article makes one non sequitur after another. This is very weird indeed. Why would Crabtree et al. argue that, since CSCW has lessons for, say, the computer games industry or for performance art, then its focus should be shifted away from work? Why abandon a line of research just because it has produced interesting and successful spin-offs? Why shift the focus away from work when this focus has produced insights - conceptually and technologically-that apparently are exceedingly valuable to other fields? Likewise, why should the arrival of interaction technologies of the contextual computing category, which are of obvious potential relevance to ordinary cooperative work settings and thus to $\mathrm{CSCW}$, motivate $\mathrm{CSCW}$ to shift its focus away from those very same ordinary cooperative work settings? Why is their potential application in ordinary cooperative work settings not even considered by Crabtree and his colleagues? Why should CSCW move away from work when these new technologies are in fact highly relevant to CSCW? Why should CSCW move in precisely this direction? Why exactly these technologies? It would of course make sense for $\mathrm{CSCW}$ to move its focus away from work if its program had been completed and if the major problems that motivated the field in the first place had been solved. 
But CSCW has not, by any standard, solved the problems of supporting 'articulation work' in complex cooperative work settings. Why abandon a progressive research program that is important in its own right? This is perplexing.

Now, could it be because the authors believe that problems of cooperative work are no longer important problems? This seems confirmed by this passage: 'As research moves out from the workplace to consider how IT may be situated in a broader range of social settings, then $\mathrm{CSCW}$ must also move with it to consider how best to inform technological development within these contexts, unless it is to run the risk of becoming a historical curiosity rather than a vibrant living research community' (Crabtree et al. 2005, p. 247.-Emphasis added). But how could CSCW possibly become 'a historical curiosity' if and as long as ordinary cooperative work is economically, demographically, socially important and if and as long as the conceptual and technical problems of developing adequate computational support for articulation work are largely and generally unsolved? Because, I suggest, the authors presume ordinary work to be of ever diminishing importance (Brown and Barkhuus in fact argue along that exact line). This interpretation solves all the puzzles: it would explain the direction Crabtree et al. argue for $\mathrm{CSCW}$ to take: 'the ludic'; it would explain why the obvious relevance of the new interaction technologies for ordinary cooperative work settings is not considered at all; it would also explain why 'business process modelling' and other technologies destined for work settings would not be considered either; and it would explain the dramatic rhetoric and the fear of being left behind when 'the times' move, the fear of becoming a relic, a mere 'historical curiosity'.

If the authors believe that ordinary work is waning, they are not alone in doing so. It has, in different shapes and forms, been the gospel of business pundits and central bankers for quite some time. Epoch-changing transformations of human society are indeed proclaimed at a frequency that seems to match the business cycle perfectly. Social scientists are as gullible (or cunning) as the next man. The 'post-industrial' society that was proclaimed by Daniel Bell (in Bell 1973) ${ }^{16}$ has been overtaken many times since - by the 'information society', 'network society', the 'new economy', and the 'knowledge-based society'. (For critical surveys of this genre, cf. Kumar 2005; Webster 2006). The refrain of all these postulates is that ordinary industrial work is on the way out, to be replaced by 'service' work, if not by leisure tout court. We are all of us, or so we are told, already or soon to become, 'symbol analysts' or 'knowledge workers' who make our income in 'virtual organizations' and dwell in 'cyber-space', in the 'weightless world' of the 'digital economy', and because of the ever-increasing amount of time at our disposal for leisure, the 'experience industry' is destined to become the big thing of the future 'leisure society'. If this was even close to being realistic, it would certainly seem as if $\mathrm{CSCW}$, with its focus on ordinary work practices, is indeed in risk of becoming 'a historical curiosity'. The problem with this, however, is that it has no foundation. 


\subsection{The myth of the 'leisure society'}

Let us take the issue of leisure first. Are we not moving into the 'leisure society' or whatever it is called: an era where work plays a diminishing role in people's lives?

Brown and Barkhuus (2007), for example, seem to refer to this when they postulate that in CSCW and in academia in general 'the importance of leisure has frequently been downplayed. There is something marginal about leisure that can let it escape our notice.' This, they think, is an 'academic reflex'. To support their assessment of the real economic and demographic importance of leisure, Brown and Barkhuus then cite a study that claims that 'time use studies show that the average European spends more time watching television than in paid employment'. They find this result 'surprising' (pp. 1-2). They do not give the details of the study; but the figures are hardly surprising: far more than half of the total population of Europe - babies, school children, students, unemployed, domestic workers, retired or disabled persons, the insane, and so on-are not 'economically active'. If one, as this study has done, presumes a 7-day week every week of the year and include the total population in the calculation, then the so-called 'average European' of course does not work much more than 2 hours per day (cf., Basso 2003, pp. 92f.).

Or did Brown and Barkhuus cite this study in order to indicate that pursuits of leisure are as economically important as, say, manufacturing? The large US motion pictures industry accounts for about $0.3 \%$ of the Gross Domestic Product of the United States. If we add radio and TV industries and 'amusement and recreation services', we get close to $2 \%$ of GDP, which is about the size of the chemical industry and about $12 \%$ of the size of manufacturing (Henwood 2005, p. 28).

Anyway, how is it with work and leisure? A few observations will suffice to give the picture.

The first thing to note, however, is that statistics about work and leisure are tricky. Data concerning the 'work week', for example, may be misleading for our purposes, since we also have to take into account paid vacations and holidays. That is, we have to measure working time on an annual basis. Furthermore, we have to take into account unemployment and other forms of unwanted 'free time', just as we should be wary of statistics of working hours based on the total population between, say the age of 15 and 64, since that number also would include students, the disabled, etc. However, there are some serious and careful studies we can build on.

In a study undertaken by the International Labour Organization (ILO), it is concluded that 'there is no question that working hours were reduced considerably during the twentieth century', but the authors are careful to point out that 'the scale of the working-hour reductions and their cross-country variations have yet to be understood'. (Lee et al. 2007, p. 24). Overall, in the 
industrialized counties of Northern Europe and North America working time has been reduced from around 3,000 hours per year in 1870 to almost half a century later (pp. 24ff.). However, it appears that 'a diverging trend came into force in the 1970s and since then the direction of working-hour changes has been reversed in some countries such as the United States' (pp. 25f.).

In fact, in the United States, working hours have been on the rise for decades. While US workers around the middle of the 19th century put in about 70 hours per week, the working week was gradually reduced to about 40 hours by the time of the Second World War, at which point it stabilized. From 1948 to 1969 this level was maintained. However, according to the authoritative study by Schor (1992, p. 79), the number of hours worked per adult per year 'rose modestly', whereas hours per labor force participant fell slightly (the difference largely reflecting the effect of women's increased participation in the work force). But then the trend shifted. 'After 1969, hours began to rise' (ibid.). During the two decades from 1969 to 1987, the hours worked by labor force participants increased from 1,786 per year to 1,949 (ibid.).

Public perceptions notwithstanding, the working conditions in 'Old Europe' are comparable. A survey study commissioned by the European Union from 1997 concludes that 'Overall Europeans work long hours' in as much as $49 \%$ of the employees work 40 hours per week or more (Paoli 1997, p. 72). According to the follow-up survey conducted in 2000, the number of employees working 40 hours per week or more had dropped to $44 \%$ (Boisard et al. 2003). Still, if we focus on hours worked by full-time employees (and excluding part-time workers), 52\% of the workers put in 40 hours or more per week. Since time spent on commuting between home and workplace can hardly be considered leisure, we should take this into account, and when we do so we find that European workers on average spend more than 3 hours per week commuting. The result is that $61 \%$ of European workers devote 40 hours per week or more to work (ibid.).

For the sake of proportions, it should be noted that workers in East Asia of course are even less close to the 'leisure society' than workers in Europe and North America. China is the obvious example. According to Judith Banister, an authority on Chinese labor statistics, in many export-oriented factories in the Pearl River Delta, the new manufacturing center of the world, 'employees usually work 6 or 7 days a week, totaling 60 to 80 hours per week in whatever period constitutes the peak season for that manufacturing sector. That season can last up to 8 months a year. Average yearly hours actually worked per employee might be as high as 4,000 hours in some China manufacturing enterprises' (Banister 2005b, p. 31). ${ }^{17}$

Altogether, if we take a global view, 'about one in five- $22.0 \%$, or 614.2 million workers - around the world are working more than 48 hours per week' (Lee et al. 2007, p. 53).

Since we are considering the presumptive need to move the focus away from work in favor of 'ludic pursuits', we should not omit the domestic or household 
work that has to be taken care of after paid work or in weekends: caring for children, shopping, cooking, cleaning, washing clothes, personal hygiene, and sleeping. In her study of the development in working hours in the US from 1969 to 1987 , Schor shows that the total hours spent by US labor force participants on paid work together with household work rose from 2,675 to 2,837 hours annually; that is, average time for leisure fell by 162 hours per year. If one considers the entire population ('working age persons'), 'leisure time has fallen by 47 hours a year' (Schor 1992, pp. 35f.). Again this is not special to the US. In the industrialized countries members of the work force on average altogether work about 80 hours per week (Goldschmidt-Clermont and Pagnossin-Aligisakis 1995; Ironmonger 2001). The fact of the matter is that the remarkable reduction of time spent on 'paid work' achieved in the course of the 20th century to a large degree has been offset by the increased engagement of women in non-domestic work. The total workload on families has not been reduced to the extent the statistics on individual working hours may lead us to believe.

The 'leisure society' is hardly imminent. Nor is there any necessity in its coming. The huge increases in productivity under the Industrial Revolution were accompanied by something in the magnitude of $100 \%$ increase of overall work time (Schor 1992, Chapter 3). The fact of the matter is that the development of technology does not in any way automatically translate into improved conditions of work and life. As pointed out by Lee et al., while economic development and income growth 'matter in reducing working hours', the 'European experience in fact indicates that the institutional framework in the country and union strength are far more important in determining working hours' (2007, p. 27). There is no supra-historical law at play in these trends. A reduction of working hours is something for which people fight and which they sometimes succeed in obtaining.

In sum, a change in the scope of CSCW cannot be motivated by references to the notion that work should play an ever-diminishing part of people's lives.

\subsection{The myth of the 'post-industrial' society}

The notion of a 'post-industrial society' is based on a rather simple idea. Just as the enormous increase in productivity in the agricultural sector of the developed countries has had the effect that the share of population of people engaged in agriculture has dropped from about $90 \%$ to something in the magnitude of $2 \%$, then the equally enormous increase in productivity in the industrial sector will have a similar effect on the level of employment in industries, with the result that the share of the population thereby made redundant can be employed in producing other kinds of commodities: 'services'. Though seductively commonsensical, the inference is faulty. While there surely is a limit to the quantity of agricultural products people can eat and drink (and stay healthy), there is no apparent limit to the development of our needs when it comes to manufactured 
goods. There simply is no mechanism that determines that industrial employment will decline as industrial productivity increases. It could very well turn out to be so, but it might just as well not turn out this way.

The notion of the 'post-industrial society' is not only conceptually flawed. Its prognostications are also based on flimsy evidence. A few observations should suffice to indicate the issues.

Proclamations that the 'industrial age' is behind us are usually buttressed by official occupational statistics that show that 'manufacturing' jobs and similar jobs in material-goods production are indeed dwindling and have long since been overtaken by jobs in the 'services' industries. True, in the developed countries, the OECD countries, the occupations categorized as 'services' have long since surpassed 'manufacturing' in numbers of people employed; they now employ approximately twice as many as 'manufacturing'. However, such statistics are useless when used as a basis for understanding structural developments and longterm trends.

First of all, the concept of 'services' is confused. ${ }^{18}$ It is a residual category under which is categorized what cannot be categorized as agriculture, 'extracting industries' (such as mining and quarrying), or material-goods production such as manufacturing and construction. The category 'services' does have a kernel of good common sense, however. Historically, 'services' was defined as work that does not result in a discrete tangible product that can be handed over to the consumer, that is, work in which the process of production and the process of consumption are collapsed temporally. Cutting somebody's hair or washing somebody's clothes is 'service' work in this classical sense. The same applies to transportation of people or goods, of course: it does not result in a discrete product; hence it is categorized as 'service' work. But here the categories begin to blur, because transportation is, to a large extent, part of production. If we then move to those large parts of the 'services' sector that are restaurants and wholesale and retail trade, confusion is massive. Wholesale and retail trade is considered 'service' because work here has an element of handling transactions and, in the case of retail trade, 'demeanor work', which evidently is not materialgoods production; but the reality is of course that a very large part of the work in these sectors consists in physical distribution of products (transportation, management of inventories, packaging) and thus actually are the last leg of the production process. Nevertheless, these disparate activities - production work, demeanor work, transaction work - are categorized wholesale as 'service'. Next, a restaurant kitchen certainly produces discrete products (this is especially obvious in the case of fast food and take-away catering), but this sector of production is considered 'service' nonetheless, probably because serving the food is transportation and demeanor work and perhaps because consumption is supposed to happen 'shortly' after production.

To make matters even worse, the occupational categorization is done at the level of company not process. A simple example will suffice to illustrate the 
problem. Many manufacturing companies have, in the course of the last few decades, been outsourcing all sorts of functions not considered critical to the "core business', such as transportation, maintenance, plant cleaning, provisioning of food and beverages, security, etc. and these have then generally been taken over by companies specialized in that kind of work. Now, since the criterion for categorization of jobs is the general categorization of the employer, not the work done within the company, and since all staff in manufacturing companies hence are categorized as manufacturing workers, this simple organizational shift shows up in the national economic and occupation statistics as a shift from manufacturing to 'services' (Huws 2003, pp. 63-67 et passim).

A related problem arises from the simple fact that national economic statistics are not economic statistics but statistics of market-mediated economic activities. Activities that are not mediated by the market, such as domestic work, volunteer work, neighborly help, as well as the vast sector of subsistence agriculture in Third World countries, fall below the statistical horizon. At best, they are referred to as the 'informal economy', but mostly they are just statistically invisible. Now, the major part of the growth of the 'service' sector reflects work that has been done for ages (preparing food, brewing beer, knitting, sewing and mending clothes, caring for children and the elderly, etc.), but was not counted because it was done in the home (typically by women), outside of the lights of the marketplace. As women become enrolled in the 'formal economy', i.e., as employees, typically in the 'service industry', the now socialized, previously domestic, tasks suddenly show up as blips on the radar screen of national economics and become categorized as 'service' work. In the national statistics this then appears as a major increase in 'service' work. But in terms of work actually done, nothing much has changed (ibid.).

Thus, as pointed out by many researchers, the concept of 'service' is confused (e.g., Huws 2003). Or to say it as clearly as possible: 'The services category is a category totally devoid of scientific value' (Basso 2003, p. 120). This makes occupational statistics largely useless with respect to understanding major changes in national and international economy.

But even leaving aside the utter meaninglessness of the 'services' category itself, the debates over the issue of the relative size of 'manufacturing' versus 'services' in OECD countries are really quite absurd; or rather, provincial. The fact that factories can no longer be seen, heard, and smelled from the suburbs of the West, is no proof that they no longer exist. It could, after all, just be an indication of regional decline. What has happened over the last two decades or so is that many industrial jobs have been 'outsourced' from the West, especially from the US and the UK, to East and South Asia and Latin America. The percentage of jobs in manufacturing (as reflected in occupational statistics) has certainly declined in the West, but, as pointed out (even) by Manuel Castells, the decline is more than offset by the increase in manufacturing in the Third World (1996, p. 253). In fact, he observes, 'While theorizing on postindustrialism we are 
experiencing [...] one of the largest waves of industrialization in history' (ibid., p. 113). Today, more than 10 years later, that wave has not subsided one bit.

If we again take the example of China, the case in point, there was a period, in the late 1990s through 2002, where the number of manufacturing workers in China was declining, caused by privatization of state- and collective-owned factories in cities and the ensuing massive layoffs and increase in productivity (Lett and Banister 2009). But in 2002, manufacturing employment 'bottomed out' at about 100 million (down from 126 in 1996): 'In recent years, with much of the redundant employment of the previous era eliminated and foreign demand for Chinese-manufactured goods growing by $25 \%$ per year, total employment has shown an upward trend', and by the end of 2006 there were 112 million manufacturing employees in China, according to Erin Lett and Judith Banister, the authority on Chinese labor statistics cited above. This is 8 times the number of manufacturing employees in the US (14 million) (Lett and Banister 2009). To give an idea of the proportions, Banister elsewhere notes that the major industrialized countries in the Group of Seven (G7) in 2002 had a total of 53 million manufacturing workers (Banister 2005a). And then we have not even considered the growth of manufacturing employment in the other industrializing countries of Asia (India, Thailand, Vietnam, Philippines, Indonesia, etc.) and in Latin America (Brazil).

We have not entered a 'post-industrial' age or a 'weightless world'. We live in the middle of an industrial revolution on a truly global scale, a massive transition from traditional agricultural work (and the domestic work and small-scale craft work connected to traditional agriculture) to industrial work.

What does that mean for CSCW? It means first of all that millions if not billions of people these years are moving from forms of work in domestic production, subsistence agriculture, and small-scale handicraft, which are only sporadically performed as cooperative work, to the generally systematic and increasingly complex cooperative work relations that characterize the industrial mode of production. More than that. The current process of industrialization in East Asia and elsewhere does not reiterate the forms the industrialization of England took two centuries ago. The historical milieux in which the current industrialization process unfolds is radically different from that of the original, of course. The process of industrialization unfolds within an already established world economy, with a global infrastructure of transportation, communication, banking, etc. Consequently, the millions of new industrial workers typically enter the world of industry in production sites that are part of global production networks, that is, they enter cooperative work relations of global scope.

In sum, focusing on ordinary work hardly makes $\mathrm{CSCW}$ 'a historical curiosity'. If somebody claims that CSCW's program, its focus on work, has to be changed, then it cannot be because work, including ordinary work in materialgoods production, has ceased to be economically, socially, or demographically important. 


\section{3. 'Work' in CSCW}

There are two arguments I am not making.

My argument is not an moral one. I am not here pontificating about an ethic of work. I am not echoing Jehovah's command, 'By the sweat of your brow you will eat your food until you return to the ground', although that obviously is true in the sense that universal and lasting abundance is not to be had in a world of finite material resources. Nor am I, though tempted, arguing in the spirit of Hesiod's admonition of his, apparently wayward, brother, Perses: 'But you must work, Perses... Gods and men disapprove of that man who lives without working... Work is no reproach, but not working is a reproach... Work, work upon work!'19 Nor am I insinuating, with Bob Dylan, that 'Some people never worked a day in their life/Don't know what work even means'. ${ }^{20}$ Although such a stance would be justifiable and might be called for, it is not the position from which I have been arguing in this article. The underlying argument is rather the pragmatic one that (increasingly complex) cooperative work relations, in the modern world economy, are critical to our ability to satisfy human needs; that the development of cooperative work relations, however, is impeded by the intricacies of coordinating (increasingly complex) cooperative work arrangements; that computer-based coordination technologies are being developed and deployed on a large scale in an attempt to somehow manage these coordinative intricacies; that these coordination technologies are primitive, unwieldy, and generally cumbersome to use; and that they have all sorts of unexpected but negative effects on cooperative work and working conditions. It was these experiences that generated the practice-oriented research program in CSCW twenty years ago and they are the ever-present motivation for pursuing this research program. But without a clear focus on cooperative work, this research program flounders (and would then have to be reinvented). By attempting to clarify the concept of 'work', I intend to justify and sharpen that focus.

My argument is not made from the position of sociology either, for sociology's concerns are irrelevant here. As a discipline, sociology treats all socially organized occasions and phenomena as in principle of equal interest. Similarly, for the sociology of work all work domains and all kinds of work are also of equal interest. The chique boutique in the city center offers instances of work that, to 'the sociological eye', are just as interesting as the work of assembling an airplane, performing heart surgery, or devising the proof of a mathematical theorem. But CSCW is not sociology, nor is it sociology of work, nor is it ethnomethodology; it is an interventionist enterprise, very much drawing on sociological competencies, of course, but committed to the development of coordination technologies for - and their transformative integration in - cooperative work practices.

CSCW's phenomenon of research is not work but cooperative work: interdependent and yet distributed work activities; and cooperative work, one 
could say, is more 'work-like' than work simpliciter. Interwoven into the web of global division of labor, cooperative work involves coping with a host of requirements, constraints, dependencies, contingencies, etc. that one does not have to deal with when working outside or at the fringe of this web: growing carrots in one's garden for one's own consumption, vacuum-cleaning one's living-room, repairing the kids' bicycles. The crucial issue is that cooperative work, especially when characterized by complex interdependencies, requires and exhibits highly developed and often sophisticated coordinative practices of a nature that one rarely, if ever, finds outside of ordinary work settings.

What coordinative practices one might find outside of ordinary cooperative work settings are typically elementary, requiring little in terms of training. In our domestic lives, we sometimes check our bank accounts and update our budgets and may use a spreadsheet program for that, but these practices are of course only superficially similar to the accounting practices we find in business firms and governmental agencies. There are also practices of coordination in domestic settings, for instance practices of using 'post-it notes' on the fridge door to make sure the youngest son is picked up from the birthday party across town or that the other parent is aware that the teenage daughter has an appointment at 7 and that dinner therefore has to be ready at 6 . But it would be frivolous to argue that the practices of scheduling in, say, producing a turbojet engine are of the same kind, only performed on a larger scale.

The phenomenon that is of particular interest to CSCW are cooperative work practices in which coordination technologies serve, or may serve, as technical resources of coordinative practices: by regulating the interdependent activities of the members of the ensemble. It is for this reason that ethnographic and other forms of in-depth workplace studies are of critical importance. We do not need ethnographic studies to be able to develop technologies for domains of activity in which we, as adults in the modern world, all engage and which we generally master (domestic life, being tourists, playing games, driving cars). That kind of technical development can be and has indeed been done successfully by designers based on their own common-sense experience (witness, e.g., the development of interactive computing). However, technologists are typically alien to professional cooperative work practices beyond their own. They therefore cannot rely on common-sense knowledge derived from their own everyday experiences to be able to develop appropriately designed coordination technologies, not to mention the computational environments for such technologies. Developing a grounded understanding of coordinative practices requires rigorous naturalistic studies as well as systematic abstraction.

\section{The Work of CSCW}

Let me end by attempting to position $\mathrm{CSCW}$ in the context of technological development. The machines of the Industrial Revolution-such as Robert's Self- 
Acting Mule spinning machine from 1825-were mechanical in the sense that the transmission of power and the control of movement were physically integrated. Power was transferred to the tool or the work piece by means of belts, cogwheels, gear trains, camshafts, and so on, and those very same parts at the same time also regulated the movements of the tool (controlled the speed, direction, etc.). To construct and modify machines required significant skill and effort, and the cost of their construction and modification were such that the use of machinery was restricted to a few branches of industry, typically mass production (Hirschhorn 1984).

This picture has changed radically with Turing's computer design: the stored program architecture. It makes it highly economical to construct control systems that are not physically integrated with the power supply. One can in fact consider the computer a universal control system: it can be made to incarnate any control function, be it that of a spinning machine, a machining center, a typesetter, or a jukebox. Now, in view of the mythological notion of 'the digital' as something non-material, it is necessary to point out that a software program that has been launched and resides in the computer's memory, in RAM, is a machine as much as the Self Acting Mule. It is just as material, it is just not tangible: one cannot touch it. However, a software machine is vastly faster because the mass of the electron is many magnitudes smaller than a cogwheel, a camshaft, a crank, etc. (the difference in magnitude is about $10^{30}$ ). It can move at a velocity close to the speed of light. What is equally important is that, when the blueprint has been designed, that is, when the source code has been written and tested, the code can be compiled and executed automatically. The costs of modifying a software machine like a spreadsheet model of a budget are insignificant compared to the cost of modifying, say, the gearbox of a car. Thus, with electronic stored-program computers (with high-level programming languages and the rest) the construction of machinery has become immensely inexpensive compared to previous technologies. The same applies to the cost of modifying such machines. And as soon as the software machine has been built, it can be copied and distributed at an insignificant cost. More than that, software machines can be linked: they can transfer data or code between themselves, and one machine can trigger the execution of another, perhaps at another location. In this way, vast machine systems are built. In fact, the Internet itself is a vast machine system that facilitates the construction and operation of other, specialized, machine systems. The economic, organizational, and social consequences of this radical reduction of the cost of producing and modifying machinery are enormous, to say the least: we live in the midst of the turmoil unleashed by this.

Whereas machinery, until a few decades ago, was rare outside of mass production industries, it is now becoming ubiquitous: from $\mathrm{CNC}$ stations and CAD plans to CT scanners and GPS navigation. Moreover, due to the development of computer network technologies, it has, in the course of merely a couple of decades, become economically feasible to construct and deploy vast 
systems of interconnected and interoperating software machines. The 'industrial' modes of working that Marx defined as working with and collaborating via 'machine systems' (1867), are now no longer confined to classical massproduction industries, but are, in important ways, becoming characteristic of all domains of work: medical work, movie production, scientific laboratories. The post-industrial society is industrial, through-and-through.

And this is where CSCW enters both the story and the history. With networked computers it is technically and economically feasible to build specialized coordination technologies, machine systems specifically designed to regulate the coordination of cooperative work activities: workflow management systems, production control systems, scheduling systems and group calendar systems, project management systems, document management systems, configuration management systems (in software engineering), medical record systems, etc., just as it is technically and economically feasible to integrate such dedicated coordination technologies with the computational tools of the trade (CNC machines, CAD plans, etc.). More importantly, it is - in principle - technically and economically feasible for these coordination technologies to be designed in such a way that ordinary workers, of whatever profession, can devise, adopt, modify, and control the rules according to which their work is coordinated by machine systems. These potentials have only been realized sporadically, however.

True, coordination technologies are being developed and deployed on a large scale. But just as communication-mediation technologies (email, instant messaging, computer conferencing) and groupware technologies (collaborative working environments such as Lotus Notes or BSCW) are of severely limited potential in modern cooperative work settings because their communication and coordination functionalities cannot be integrated with other work tools, - - these specialized coordination technologies suffer from identical limitations: their coordination functionalities cannot be integrated with other work tools and they are mutually closed. CAD systems, for instance, only provide support for 'mutual awareness' or for workflows to the extent that such functionality is built into the application program, in which case they would not interface with the project and document management systems that might also be a part of the technical repertoire of the given practice. And so on. The research program that was outlined twenty years ago - by Irene Greif and others ${ }^{21}$ - is as topical and as necessary as ever. This limitation is fundamental and cannot be overcome simply by a few application program interfaces (APIs). The limitation is conceptual and is a limitation of current computing technology. It is a limitation of the 'assumed model of use'. To overcome the limitation requires the 'abstraction' Greif called for (Greif 1988, p. 8): identification of a set of object and operation 'primitives' and a set of rules of combination that are shared by all applications and that enable designers and users to communicate about and coordinate their interdependent activities from within any application. For interactive computing technologies this abstraction was achieved by the identification of objects such as 
character, word, sentence, etc. and operations such as COPY, MOVE, PASTE, DELETE, etc. For messaging technologies this was achieved by the identification of primitives such as FROM, TO, SUBJECT, etc. The major challenge for CSCW is to pursue the 'necessary abstraction' in a systematic manner, so as to be able to facilitate the coordination of cooperative work across specialized work tools, that is, facilitate 'mutual awareness', direction of attention, determination of task sequence and priority, categorization of objects and tasks, etc. But while the technologists who developed interactive computing (especially the developers of the Xerox Alto in the 1970s) and the developers of electronic mail could build on their own experiences as members of cooperative work settings, CSCW researchers are in an entirely different situation: we have to understand the logics of coordinative practices to be able to identify those elemental categories and techniques and the ways in which they may be combined and thereby develop the required conceptual and technical basis for a general coordination technology. This requires systematic ethnographic studies of professional coordinative practices (as well as experimental design and systematic evaluation, etc.).

As far as this research program is concerned, however, $\mathrm{CSCW}$ has only made modest progress. In spite of some stellar research contributions over the years, most ethnographic and constructive work has stopped short of engaging in what Greif calls the 'necessary abstraction' of identifying elemental categories and techniques that are or can be made general as part of a CSCW-enhanced network technology. There are probably many reasons for that. The result is anyway that our understanding of cooperative work in general and the logics of coordinative practices in particular is deficient, vague, patchy. But it is not difficult to realize what is required to overcome this predicament: focus!

\section{Acknowledgments}

The research has been supported by a research grant from the University of Siegen, Germany.-I would like to acknowledge the (critical or supportive) contributions of the participants in the plenary discussions at ECSCW 2009 and at COOP 2010. I would also like to express my gratitude to the anonymous reviewers who, despite being 'irritated' by my enterprise, recommended or requested that I elaborate my exposition significantly.

\section{Notes}

1. Cf. http://www.springer.com/series/2861.

2. Cf. http://cscw2011.org/ and http://www.cscw2012.org/.

3. The present article is based on a paper entitled "'Keep up the good work!": The concept of "work" in CSCW' that was presented at COOP 2010 in Aix-en-Provence, France (Schmidt 2010). In response to the ensuing debates at COOP 2010 as well as to the requests of the anonymous reviewers, the current version has been updated, reworked, expanded, and - hopefully - made more clear.

4. It takes some stretch of 'sociological imagination' to extend the concept of the 'ludic' to include, of all things, domestic life. 
5. It should be noted, also in passing, that it requires more than 'sociological imagination' to claim that 'awareness, division of labour, collaboration, distribution of tasks, efficiency and even workflow [...] exist in our leisure lives as much as [in] our work' (emphasis added).

6. One may object that conversation analysis has most certainly been cumulative but as pointed out by Sharrock and Anderson, it has been so because of its specificity: 'The admirable thing about conversational analysis is not the generality of its methods, but their specificity. Conversational analysis has not provided methods for the analysis of social organization, or even of social interaction, it has provided methods for the analysis of conversation.' (Sharrock and Anderson 1986, p. 80).

7. "How do I recognize that this colour is red?-One answer would be: "I have learnt English." (Wittgenstein 1945-46, § 381).

8. In an earlier version of this argument, Wittgenstein formulates this in a slightly different but illuminating way: 'One says: the use of the same word is inessential here, because the identity of the shape of the word does not here serve to mediate a transition. But in saying that one is merely describing the game that one wants to play.' (Wittgenstein 1937-44, Part I, Appendix 1 (1933-34), § 26). The use of the same word may 'mediate a transition', i.e., suggest a parallel, an analogy, an association, an allegory, and so on, which may or may not be of import in the specific domain of discourse or in the particular language-game.

9. Clifford Geertz has highlighted the importance of this conception for ethnography (and, by implication, for CSCW). Discussing another of Ryle's examples (describing the rapid contraction of an eyelid as 'winking'), he says: '[The] point is that between what Ryle calls the "thin description" of what the rehearser (parodist, winker, twitcher...) is doing ("rapidly contracting his right eyelids") and the "thick description" of what he is doing ("practicing a burlesque of a friend faking a wink to deceive an innocent into thinking a conspiracy is in motion") lies the object of ethnography: a stratified hierarchy of meaningful structures in terms of which twitches, winks, fake-winks, parodies, rehearsals of parodies are produced, perceived, and interpreted, and without which they would not $[\ldots]$ in fact exist, no matter what anyone did or didn't do with his eyelids.' 'If ethnography is thick description and ethnographers those who are doing the describing, then the determining question for any given example of it, whether a field journal squib or a Malinowski-sized monograph, is whether it sorts winks from twitches and real winks from mimicked ones.' (Geertz 1973, pp. 7, 16).

10. Johnny Cash: The Johnny Cash Show, Columbia Records, October 1970. (Song lyrics by Dave Dudley, 1963).

11. In the words of Aristotle (c. 334-322 BCE) (in his Metaphysics), "everything called "healthy" has some reference to health, such as preserving it, or producing it, or being an indication of it, or being capable of it' and can therefore be said to 'refer back to a single root' (Book IV, §2).

12. This usage seems to be an English specialty, derived from the word's Germanic root ('wirken': to take effect). In German one distinguishes between Tätigkeit (mere activity) and Wirksamkeit (effective activity).

13. It should be noticed that the widely cited article of the same title (Sacks 1970-71) consists of parts of this lecture that the editor, Gail Jefferson, put together with pieces of text extracted from other lectures to form what is little more than a collage. Jefferson also replaced the conversation transcripts under discussion with transcripts from other lectures, changing the names of conversationalists in the process.

14. Isn't this like saying that the work of carpenters consists in gluing?

15. "Conversation analysts ... [are] concerned that using terms such as "doctor's office", "courtroom", "police department", "school room", and the like, to characterise settings ... can obscure much of what occurs within those settings ... For this reason, conversation analysts rarely rely on ethnographic data and instead examine if and how interactants themselves reveal an orientation to institutional or other contexts.' (Maynard and Clayman 1991, quoted in Silverman 1998, p. 163).- At this point the path of conversation analysis diverges from that of ethnomethodology. Michael Lynch, for example, points out that the use of video and audio recordings 'in detailing constituent structures of any particular order of work requires an argument for how that work is visible in that way as a consequential production of the setting studied'. Their analytic use 'requires a demonstration of the relevance of bodily movement and talk as a repository of the detailed make-up of the work's accountability' (Lynch 1985, p. 7). Lynch goes on to argue that studies of conversation are a 'double-edged' resource for studies of specific work settings because they, while providing 'an easy way to produce analytical findings', in fact leave 'the specific and substantive character of the work being done in-and-through the conversation unexplicated' (Lynch 1985, pp. 8f.). 
16. It should be noted, in all fairness, that Bell was a scholar 'of powerful imagination and intellect', as Frank Webster rather generously puts it, and that his book, for all its flaws, is still worth reading: The notion of the Post-Industrial Society 'may be inadequately conceived and empirically flawed, contradictory and inconsistent, but [his book] is, to borrow a phrase from George Orwell, a "good bad book". Futurists like Alvin Toffler, Nicholas Negroponte and John Naisbitt, whose paperback speculations capture the largest audiences, merely produce bad books: intellectually slight, derivative, analytically inept and naïve on almost every count. Daniel Bell, on the other hand, produces 'good bad” books.' (Webster 2006, p. 35).

17. For voices of those involved, cf. Leslie Chang's accounts from Dongguan (2008).

18. Jonathan Gershuny has done a great deal to sort out this mess (Gershuny and Miles 1983; Gershuny 1983).

19. Hesiod: Work and Days (8th Cent. BCE).

20. Bob Dylan: 'Workingman's Blues \#2', Modern Times, Sony Records, 2006.

21. This practice-oriented research program was formulated in different but converging ways (cf. e.g., Greif 1988; Bannon and Schmidt 1989; Pankoke-Babatz 1989; Rodden and Blair 1991; Rodden et al. 1992; Schmidt and Bannon 1992; Hughes et al. 1994).

\section{References}

Aristotle (c. 334-322 BCE). (1952). Metaphysics. New York: Columbia University Press. Transl. by R. Hope.-Ann Arbor: University of Michigan Press, 1960 (Paperback ed.).

Austin, J. L. (1956-57). A plea for excuses (Proceedings of the Aristotelian Society, 1956-57). Text ed. by J. O. Urmson and G. J. Warnock. In J. L. Austin, Philosophical papers (pp. 175-204). Oxford: Oxford University Press, 1979. (3rd ed.; 1st ed. 1961).

Baker, G. P., \& Hacker, P. M. S. (1984). Language, sense and nonsense: A critical investigation into modern theories of language. Oxford: Blackwell.

Baker, G. P., \& Hacker, P. M. S. (2005). Wittgenstein: Understanding and meaning. Part I: Essays. Oxford: Basil Blackwell (G. P. Baker \& P. M. S. Hacker: An analytical commentary on the Philosophical investigations, vol. 1). (2nd rev. ed.; 1st ed. 1980).

Bambrough, R. (1961-62). Universals and family resemblances. Proceedings of the Aristotelian Society, New Series, 61, 207-222.

Banister, J. (2005a). Manufacturing employment in China. Monthly Labor Review, 128(7), 11-29.

Banister, J. (2005b). Manufacturing earnings and compensation in China. Monthly Labor Review, 128(8), 22-39.

Bannon, L. J., \& Schmidt, K. (1989). CSCW: Four characters in search of a context. In P. Wilson, J. M. Bowers, \& S. D. Benford (Eds.), ECSCW'89: Proceedings of the 1st European Conference on Computer Supported Cooperative Work, 13-15 September 1989, Gatwick, London (pp. 358372). London.

Basso, P. (2003). Modern times, ancient hours: Working lives in the twenty-first century. London and New York: Verso. Transl. by G. Donis. Text ed. by G. Donis.

Bell, D. (1973). The coming of post-industrial society: A venture in social forecasting. New York: Basic Books.

Boisard, P., Cartron, D., Gollac, M., \& Valeyre, A. (2003). Time and work: Duration of work. Dublin: European Foundation for the Improvement of Living and Working Conditions.

Bourdieu, P. (1980). Le sens pratique. Paris: Les Éditions de Minuit.

Bowers, J. M., Churcher, J., \& Roberts, T. (1988). Structuring computer-mediated communication in COSMOS. In R. Speth (Ed.), EUTECO'88: European Teleinformatics Conference on Research into Networks and Distributed Applications, 20-22 April 1988, Vienna, Austria. Organized by the European Action in Teleinformatics COST 11ter (pp. 195-209). Brussels and Luxemburg: North-Holland.

Brown, B., \& Barkhuus, L. (2007). Leisure and CSCW: Introduction to special edition. Computer Supported CooperativeWork (CSCW): The Journal of Collaborative Computing, 16(1-2), 1-10. 
Button, G., Coulter, J., Lee, J. R. E., \& Sharrock, W. W. (1995). Computers, minds and conduct. Cambridge: Polity Press.

Castells, M. (1996). The rise of the network society, (Vol. 1). Oxford: Blackwell.

Chang, L. T. (2008). Factory girls: Voices from the heart of modern China. New York: Spiegel \& Grau. — London: Picador, 2009 (Paperback ed.).

Crabtree, A., Rodden, T. A., \& Benford, S. D. (2005). Moving with the times: IT research and the boundaries of CSCW. Computer Supported Cooperative Work (CSCW): The Journal of Collaborative Computing, 14(3), 217-251.

Crabtree, A., Rodden, T. A., Tolmie, P., \& Button, G. (2009). Ethnography considered harmful. In R. B. Arthur et al. (Eds.), CHI 2009: Proceedings of the 27th International Conference on Human Factors in Computing Systems, Boston, Mass., 4-9 April 2009 (pp. 879-888). New York: ACM Press.

Fogelin, R. J. (1987). Wittgenstein. London and New York: Routledge \& Kegan Paul. (2nd ed.; 1st ed. 1976).

Garfinkel, H. (1967). Studies in ethnomethodology. Englewood-Cliffs: Prentice-Hall. — Cambridge: Polity Press, 1987.

Garfinkel, H. (Ed.) (1986). Ethnomethodological studies of work. London: Routledge \& Kegan Paul.

Garfinkel, H., Lynch, M., \& Livingston, E. (1981). The work of a discovering science construed with materials from the optically discovered pulsar. Philosophy of the Social Sciences, 11, 131-158.

Gaver, W. W. (2001). Designing for ludic aspects of everyday life. ERCIM News: Online edition, no. 47, 2001. <http://www.ercim.org/publication/Ercim_News/enw47/gaver.html>

Gaver, W. W. (2002). Provocative awareness. Computer Supported Cooperative Work (CSCW): The Journal of Collaborative Computing, 11(3-4), 475-493.

Geertz, C. (1973). The interpretation of culture: Selected essays. New York: Basic Books.

Gershuny, J. I. (1983). Social innovation and the division of labour. Oxford: Oxford University Press.

Gershuny, J. I., \& Miles, I. D. (1983). The new service economy: The transformation of employment in industrial societies. London: Frances Pinter.

Goffman, E. (1955). On face-work: An analysis of ritual elements in social interaction. Psychiatry: Journal for the Study of Interpersonal Processes, 18, 213-231.

Goffman, E. (1959). The presentation of self in everyday life. New York: Anchor Books.

Goffman, E. (1961). Encounters: Two studies in the sociology of interaction. Indianapolis: BobbsMerrill.

Goldschmidt-Clermont, L., \& Pagnossin-Aligisakis, E. (1995). Measures of unrecorded economic activities in fourteen countries. United Nations Development Programme, New York, 31 January 1995. Human Development Reports.—Occasional Papers \#20. <http://hdr.undp.org/en/reports/ global/hdr1995/papers/luisella_goldschmidt-clermont.pdf>

Greif, I. (1988). Overview. In I. Greif (Ed.), Computer-Supported Cooperative Work: A book of readings (pp. 5-12). San Mateo, Calif.: Morgan Kaufmann.

Hacker, P. M. S. (1990). Wittgenstein: Meaning and mind. Oxford: Basil Blackwell. (G. P. Baker and P. M. S. Hacker: An analytical commentary on the Philosophical Investigations, vol. 3).

Hacker, P. M. S. (1996a). Wittgenstein's place in twentieth-century analytic philosophy. Oxford: Blackwell.

Hacker, P. M. S. (1996b). Wittgenstein: Mind and will. Oxford: Basil Blackwell (G. P. Baker and P. M. S. Hacker: An analytical commentary on the Philosophical Investigations, vol. 4).

Hacking, I. (1975). Why does language matter to philosophy? Cambridge: Cambridge University Press.

Henwood, D. (2005). After the new economy. New York and London: The New Press (1st ed. 2003).

Heritage, J. C. (1984). Garfinkel and ethnomethodology. Cambridge: Polity. 
Hirschhorn, L. (1984). Beyond mechanization: Work and technology in a postindustrial age. Cambridge, Mass.: MIT Press.

Hughes, J. A., Randall, D. W., \& Shapiro, D. Z. (1991). CSCW: Discipline or paradigm? A sociological perspective. In L. J. Bannon, M. Robinson, \& K. Schmidt (Eds.), ECSCW'91: Proceedings of the Second European Conference on Computer-Supported Cooperative Work, 24-27 September 1991, Amsterdam (pp. 309-323). Dordrecht: Kluwer Academic Publishers.

Hughes, J. A., et al. (1994). Perspectives on the social organisation of work. In J. A. Hughes et al. (Eds.), Field studies and CSCW. Lancaster, UK: Computing Department, Lancaster University, October 1994 (pp. 129-160). COMIC Deliverable D2.2. <http://www.comp.lancs.ac.uk/ computing/research/soft_eng/comic/>

Huws, U. (2003). The making of a cybertariat: Virtual work in a real world. New York: Monthly Review Press.

Ironmonger, D. S. (2001). Household production and the household economy. In N. J. Smelser \& P. B. Baltes (Eds.), Encyclopedia of the social \& behavioral sciences. Oxford: Elsevier Science.

James, W. (1890). The principles of psychology. Volume two. New York: Henry Holt \& Co.. New York: Dover Publications, 1950.

Kumar, K. (2005). From post-industrial to post-modern society: New theories of the contemporary world. Malden, Mass., and Oxford: Blackwell (2nd ed.; 1st ed., 1995).

Lee, S. H., McCann, D. M., \& Messenger, J. C. (2007). Working time around the world: Trends in working hours, laws, and policies in a global comparative perspective. Geneva: ILO.

Lett, E., \& Banister, J. (2009). China's manufacturing employment and compensation costs: 2002 06. Monthly Labor Review, 132(4), 30-38.

Livingston, E. (1986). The ethnomethodological foundations of mathematics. London: Routledge \& Kegan Paul.

Lynch, M. (1985). Art and artifact in laboratory science: A study of shop work and shop talk in a research laboratory. London: Routledge \& Kegan Paul.

Martin, D., \& Rouncefield, M. (2003). Making the organization come alive: talking through and about the technology in remote banking. Human-Computer Interaction, 18(1-2), 111-148.

Marx, K. (1857-58). Grundrisse der Kritik der politischen Ökonomie (Manuscript, 1857-58). Text ed. by V. K. Brušlinskij; L. R. Mis'kevič; and A. G. Syrov. In K. Marx, \& F. Engels, Gesamtausgabe (MEGA(2)) (vol. II/1, pp. 47-747). Berlin: Dietz Verlag, 1976-1981.

Marx, K. (1867). Das Kapital. Kritik der politischen Ökonomie. Erster Band. Buch I: Der Produktionsprocess des Kapitals (Hamburg, 1867). Text ed. by E. Kopf, et al. In K. Marx, \& F. Engels, Gesamtausgabe (MEGA(2)) (vol. II/5). Berlin: Dietz Verlag, 1983.

Moerman, Mi., \& Sacks, H. (1971). On "understanding" in the analysis of natural conversation (American Anthropological Association, New York, 20 November 1971). In M. Moerman, Talking culture: Ethnography and conversation analysis (pp. 180-186). Philadelphia: University of Pennsylvania Press, 1988.

Pankoke-Babatz, U. (Ed.). (1989). Computer based group communication: The AMIGO activity model. Chichester: Ellis Horwood Publishers.

Paoli, P. (Ed.). (1997). Second European survey on working conditions. Dublin: European Foundation for the Improvement of Living and Working Conditions.

Pitkin, H. F. (1972). Wittgenstein and justice: On the significance of Ludwig Wittgenstein for social and political thought. Berkeley: University of California Press (Paperback ed., 1993).

Prien, B. (2004). Family resemblances: a thesis about the change of meaning over time. Kriterion, $18,15-24$.

Randall, D. W., \& Hughes, J. A. (1995). Sociology, CSCW, and working with customers. In P. J. Thomas (Ed.), The social and interactional dimensions of human-computer interfaces (pp. 142160). Cambridge: Cambridge University Press. 
Randall, D. W., Harper, R. H. R., \& Rouncefield, M. (2007). Fieldwork for design: Theory and practice. London: Springer.

Rodden, T. A., \& Blair, G. (1991). CSCW and distributed systems: The problem of control. In L. J. Bannon, M. Robinson, \& K. Schmidt (Eds.), ECSCW'91: Proceedings of the Second European Conference on Computer-Supported Cooperative Work, 24-27 September 1991, Amsterdam (pp. 49-64). Dordrecht: Kluwer Academic Publishers.

Rodden, T. A., Mariani, J. A., \& Blair, G. (1992). Supporting cooperative applications. Computer Supported Cooperative Work (CSCW): An International Journal, 1(1-2), 41-68.

Ryave, A. L., \& Schenkein, J. N. (1974). Notes on the art of walking. In R. Turner (Ed.), Ethnomethodology: Selected readings (pp. 265-274). Harmondsworth: Penguin Books.

Ryle, G. (1951). Thinking and language (Proceedings of the Aristotelian Society, 1951). In G. Ryle, Collected papers. Volume II: Collected essays, 1929-1968 (pp. 258-271). London: Hutchinson \& Co.. 1971.

Ryle, G. (1966-67). Thinking and reflecting (Royal Institute of Philosophy Lectures, 1966-67). In G. Ryle, Collected papers. Volume II: Collected essays, 1929-1968 (pp. 465-479). London: Hutchinson \& Co, 1971.

Ryle, G. (1968). The thinking of thoughts: What is "le Penseur" doing? (University Lectures, University of Saskatchewan, 1968). In G. Ryle, Collected papers. Volume II: Collected essays, 1929-1968 (pp. 480-496). London: Hutchinson \& Co.. 1971.

Sacks, H. (1970). Doing "being ordinary" (Lecture, University of California, Irvine, Spring 1970). Text ed. by G. Jefferson. In H. Sacks (Ed.), Lectures on conversation (Vol. II, pp. 215-221). Malden, Mass. and Oxford: Blackwell, 1992.

Sacks, H. (1970-71). On doing "being ordinary" (1970-71). Text ed. by G. Jefferson. In J. M. Atkinson, \& J. C. Heritage (Eds.), Structures of social action: Studies in conversation analysis. (pp. 413-429). Cambridge etc.: Cambridge University Press \& Editions de la Maison des Sciences de l'Homme, 1984.

Sacks, H. (1971). Caller-called (Lecture, University of California, Irvine, 19 April 1971). Text ed. by G. Jefferson. In H. Sacks, Lectures on conversation (Vol. II, pp. 360-366). Malden, Mass., and Oxford: Blackwell, 1992.

Sacks, H., Schegloff, E. A., \& Jefferson, G. (1974). A simplest systematics for the organization of turn-taking for conversation. Language, 50(4), 696-735.

Savigny, E. von (1998). Sprachspiele und Lebensformen: Woher kommt die Bedeutung? In E. von Savigny (Ed.), Ludwig Wittgenstein: Philosophische Untersuchungen (pp. 7-40). Berlin: Akademie Verlag.

Schmidt, K. (1991). Riding a tiger, or computer supported cooperative work. In L. J. Bannon, M. Robinson, \& K. Schmidt (Eds.), ECSCW'91: Proceedings of the Second European Conference on Computer-Supported Cooperative Work, 24-27 September 1991, Amsterdam (pp. 1-16). Dordrecht: Kluwer Academic Publishers.

Schmidt, K. (2009). Divided by a common acronym: On the fragmentation of CSCW. In I. Wagner et al. (Eds.), ECSCW 2009: Proceedings of the 11th European Conference on Computer-Supported Cooperative Work, 7-11 September 2009, Vienna, Austria (pp. 223-242). London: Springer.

Schmidt, K. (2010). "Keep up the good work!": The concept of "work" in CSCW. In M. Lewkowicz et al. (Eds.), COOP 2010: 9th International Conference on the Design of Cooperative Systems, 18-21 May 2010, Aix-en-Provence, France (pp. 265-286). London: Springer.

Schmidt, K. (2011). Cooperative work and coordinative practices: Contributions to the conceptual foundations of Computer-Supported Cooperative Work (CSCW). London: Springer.

Schmidt, K., \& Bannon, L. J. (1992). Taking CSCW seriously: Supporting articulation work. Computer Supported Cooperative Work (CSCW): An International Journal, 1(1-2), 7-40.

Schor, J. B. (1992). The overworked American: The unexpected decline of leisure. New York: Basic Books (Paperback ed., 1993). 
Schütz, A. [A. Schutz] (1944). The stranger: An essay in social psychology (American Journal of Sociology, 1944). Text ed. by A. Brodersen. In A. Schutz, Collected papers. Vol. II. Studies in social theory (pp. 91-105). The Hague: Martinus Nijhoff, 1964.

Schütz, A. [A. Schutz] (1945). On multiple realities (Philosophy and Phenomenological Research, June 1945). Text ed. by M. Natanson. In A. Schutz, Collected papers. Vol. I. The problem of social reality (pp. 207-259). The Hague: Martinus Nijhoff, 1962.

Schütz, A. [A. Schutz] (1953). Common-sense and scientific interpretations of human action (Philosophy and Phenomenological Research, September 1953). Text ed. by M. Natanson. In A. Schutz, Collected papers. Vol. I. The problem of social reality (pp. 3-47). The Hague: Martinus Nijhoff, 1962.

Sharrock, W. W., \& Anderson, R. J. (1986). The ethnomethodologists. Chichester: Ellis Horwood Publishers.

Silverman, D. (1998). Harvey Sacks: Social science and conversation analysis. Cambridge: Polity Press.

Sluga, H. (2006). Family resemblance. Grazer Philosophische Studien, 71, 1-21.

Smith, H. T. (1988). The requirements for group communication services. In R. Speth (Ed.), EUTECO'88: European Teleinformatics Conference on Research into Networks and Distributed Applications, 20-22 April 1988, Vienna, Austria. Organized by the European Action in Teleinformatics COST 11ter (pp. 89-95). Brussels and Luxemburg: North-Holland.

Strauss, A. L. (1985). Work and the division of labor. The Sociological Quarterly, 26(1), 1-19.

Sudnow, D. (1978). Ways of the hand: The organization of improvised conduct. Cambridge, Mass.: Harvard University Press.

Turner, R. (1974). Introduction. In R. Turner (Ed.), Ethnomethodology: Selected readings (pp. 712). Harmondsworth: Penguin Books.

Urmson, J. O. (1970). Polymorphous concepts. In O. P. Wood \& G. Pitcher (Eds.), Ryle: A collection of critical essays (pp. 249-266). Garden City: Doubleday. — London: Macmillan, 1971.

Webster, F. (2006). Theories of the information society. London and New York: Routledge. (3rd ed.; 1st ed. 1995.).

Wennerberg, H. (1967). The concept of family resemblance in Wittgenstein's later philosophy. Theoria, 33(2), 107-132.

White, A. R. (1967). The philosophy of mind. New York: Random House.

Wittgenstein, L. (1931-34). Philosophische Grammatik (Manuscript, 1931-34). Text ed. by R. Rhees. In L. Wittgenstein, Philosophische Grammatik. Frankfurt am Main: Suhrkamp, 1984. (Werkausgabe in 8 Bänden, vol. 4).

Wittgenstein, L. (1934-35). The brown book (Manuscript, 1934-35). Text ed. by R. Rhees. In L. Wittgenstein, The blue and brown books: Preliminary studies for the Philosophical investigations; generally known as the Blue and Brown books (pp. 75-185). Oxford: Basil Blackwell Publishers, 1969. (2nd ed.; 1st ed 1958).

Wittgenstein, L. (1937-44). Remarks on the foundations of mathematics (Manuscript, 1937-44). Transl. from Bemerkungen über die Grundlagen der der Mathematik. Transl. by G. E. M. Anscombe. Text ed. by G. H. von Wright; R. Rhees; and G. E. M. Anscombe. Oxford: Basil Blackwell Publishers, 1978. (Revised ed.; 1st ed. 1956).

Wittgenstein, L. (1945-46). Philosophical investigations (Manuscript, 1945-46). Transl. from Philosophische Untersuchungen. Transl. by G. E. M. Anscombe; P. M. S. Hacker; and J. Schulte. Text ed. by P. M. S. Hacker and J. Schulte. In L. Wittgenstein, Philosophical investigations (pp. 1-181). Oxford: Blackwell Publishers, 2009. (Revised 4th ed.).-TS 227: Previously published as Philosphical investigations, Part 1.

Wittgenstein, L. (1945-48). Zettel (Manuscript, 1945-48). Transl. by G. E. M. Anscombe. Text ed. by G. E. M. Anscombe and G. H. von Wright. Oxford: Basil Blackwell Publishers, 1981. (2nd ed; 1st ed. 1967).

Wittgenstein, L. (1949-51). On certainty (Manuscript, 1949-51). Transl. from Über Gewißheit. Transl. by D. Paul and G. E. M. Anscombe. Text ed. by G. E. M. Anscombe and G. H. von Wright. Oxford: Basil Blackwell Publishers, 1975. (2nd ed.; 1st ed. 1969). 